\title{
EL ARZOBISPO DON ALONSO II DE FONSECA. NOTAS PARA SU ESTUDIO
}

\author{
Por \\ MERCEDES VÁZQUEZ BERTOMEU ${ }^{1}$
}

El período histórico ocupado por el pontificado de don Alonso de Fonseca, segundo de este nombre, ha suscitado siempre un gran interés en los historiadores. Ello se debe, no tanto a la compleja personalidad del prelado, como a los difíciles acontecimientos que le tocó vivir y, sobre todo, a su decisiva intervención en ellos. En efecto, la participación del arzobispo en los conflictos de la Galicia de la segunda mitad del siglo XV es sobradamente conocida en sus rasgos más generales, aunque no de modo preciso, tanto en lo referente al discurrir cronológico, como respecto a las causas y razones que motivaron los posicionamientos y actuaciones de este personaje $\mathrm{e}^{2}$. La calidad de ciertas fuentes históricas y la magnitud de

\footnotetext{
${ }^{1}$ El presente artículo ha sido realizado dentro del proyecto de investigación: Inventario documental e gráfico das fortalezas medievais de Galicia (XUGA-40101B97).

${ }^{2}$ LÓPEZ FERREIRO, A.: Historia de la Santa Apostólica y Metropolitana Iglesia de Santiago de Compostela. 11 vols. Santiago, 1898-1909; v. VII, pp. 242 y ss.; LÓPEZ FERREIRO, A.: Galicia en el último tercio del siglo XV. Reed. Santiago de Compostela, 1968; p. 26 y ss.; PORTELA PAZOS, S.: Galicia en el tiempo de los Fonseca. Madrid, 1957; pp. 28 y ss. GARCÍA ORO, J.: Galicia en los siglos XIV y XV. 2 vols. La Coruña, 1987 ; v. II, pp. 55 y ss. Centrados en la posición del prelado ante el conflicto irmandiño: MACKENZIE, D.: «Alonso de Fonseca Acevedo and the Irmandiño Rising» en Essays in honour of Robert Brian Tate from his colleagues and pupils. Nottingam, 197?; pp. 5970; PARDO DE GUEVARA Y VALDÉS, E.: «El arzobispado de Santiago en tiempos de don Alonso II de Fonseca» en Hispania Sacra, v. XXX (1977), pp. 183-200.
}

"CUADERNOS DE ESTUDIOS GALLEGOS", Tomo XLVII, Fascículo 112, Santiago 2000. 
los acontecimientos sin duda contribuyeron a moldear esta actitud de los estudiosos ${ }^{3}$ y es, por ello, que importantes aspectos del mandato de Don Alonso permanecen casi desconocidos a causa, sobre todo, de la dispersión y fragmentación de la documentación disponible. Existen, no obstante, en nuestros días estudios y documentación disponible que permiten una aproximación más completa al personaje, sus circunstancias y labor al frente de la Iglesia compostelana. Todo este material debe ser confrontado y valorado en busca de una reinterpretación más certera de los acontecimientos de la segunda mitad del siglo XV.

El mandato de Don Alonso de Fonseca al frente de la Iglesia compostelana está a todas luces -y muy especialmente en los primeros deceniospresidido por las dificultades. Desde luego no es el único personaje que sufre estas circunstancias, aunque sí parece que muy especialmente en su caso éstas condicionan no sólo su personalidad, sino la imagen que de él ha conformado la historiografía. Así, esta intensa trayectoria vital ha quedado reducida en la investigación contemporánea al estereotipo del prelado guerrero e iracundo, un tanto alejada de la visión -siempre subjetivade sus contemporáneos. Las páginas siguientes tienen como único propósito exponer las líneas generales de su biografía y de su gestión al frente de la Iglesia compostelana, reuniendo la información disponible para conformar un cuadro - que se pretende equilibrado- de este personaje, un punto de partida para acercamientos futuros.

\section{ALONSO DE FONSECAY ACEVEDO: NOTAS BIOGRÁFICAS}

La biografía de este arzobispo en el período anterior a su llegada a Santiago apenas puede reconstruirse sobre noticias precisas; de hecho, y de modo incuestionable, la primera información contrastada sobre él se

\footnotetext{
${ }^{3}$ Tanto el documento conocido como Pleito Tabera-Fonseca (editado por A. RODRÍGUEZ GONZÁLEZ: Las fortalezas de la Mitra Compostelana y los Irmandiños. Santiago de Compostela, 1984) como la obra de Vasco de Aponte Recuento de las casas antiguas del reino de Galicia (Santiago de Compostela, 1986) -si bien por distintas razones-, ponen su énfasis en los acontecimientos de la Revuelta Irmandiña y en la participación en ella y en los sucesos anteriores y posteriores de los caballeros gallegos entre los que se encuentra el prelado compostelano.
}

"CUADERNOS DE ESTUDIOS GALLEGOS", Tomo XLVII, Fascículo 112, Santiago 2000. 
refiere a su presencia en Sevilla, junto a su homónimo tío -por entonces prelado de aquella iglesia- actuando como deán hispalense ${ }^{4}$.

Tradicionalmente se le ha considerado como nacido en Salamanca, donde se asientan las familias Fonseca y Acevedo, que ocupan en la ciudad una posición señalada , hijo de Diego González de Acevedo y Catalina de Fonseca y Ulloa. Su tío Don Alonso, primero obispo de Ávila y luego de Sevilla, es un personaje relevante en la política del reino, especialmente con Enrique IV; otro prelado homónimo -perteneciente a la misma parentela- ocupó las sedes de Ávila, Cuenca y Osma ${ }^{6}$. Se trata, pues, de un individuo perteneciente a un linaje de cierta importancia -aunque en ascenso- cuya carrera, sin duda, se desarrolla al amparo de familiares influyentes. Son varios los autores que atribuyen al prelado compostelano un doctorado en leyes y cánones en la facultad de Padua, sin que pueda por el momento confirmarse esta afirmación ${ }^{7}$. Noticias igualmente confu-

${ }^{4}$ ORTIZ DE ZÚÑIGA, M.: Annales eclesiásticos y seculares de la muy noble y muy leal ciudad de Sevilla. Reimp. Sevilla, 1988; v. II, pp. 17-19, 25 y ss.; PORTELA PAZOS, S.: Galicia, p. 34.

${ }^{5}$ Sobre los principales linajes salmantinos de la segunda mitad del siglo XV -entre los que destaca el grupo formado por los Fonseca, Acevedo y Maldonado-, vd. LÓPEZ BENITO, C.I.: La nobleza salmantina ante la vida y la muerte (1476-1535). Salamanca, 1991; y de la misma autora Bandos nobiliarios en Salamanca. Salamanca, 1983. La genealogía de la familia Fonseca ha merecido también la atención de varios investigadores: ALCOCER Y MARTÍNEZ, M.: D. Juan Rodríguez de Fonseca. Estudio críticobiográfico.Valladolid, 1926; pp. 9-15; PARDO DE GUEVARA Y VALDÉS, E.: op. cit., pp. 190- 195; SAGARRA GAMAZO, A.: «El protagonismo de la familia Fonseca, oriunda de Portugal y asentada en Toro en la política castellana hasta el descubrimiento de América» en Anuario del Instituto de Estudios Zamoranos Florián de Ocampo (1993), pp. 421-457.

${ }^{6}$ Una biográfia sintética de ambos prelados pueden encontrarse en Diccionario de Historia Eclesiástica de España. Madrid, 1975; vol. Suplemento, p. 322-327 y 327-329. Véase también la semblanza que del primero realiza Fernando del Pulgar en Claros Varones de Castilla (Sevilla, 1500; pp. 37-38).

${ }^{7}$ PORTELA PAZOS, S.: Galicia, p. 34. ORTIZ DE ZÚÑIGA, M.:Annales, p. 17. Este último autor, no obstante, menciona una estancia de Fonseca en Padua como estudiante, sin llegar a alcanzar grado alguno. Sin embargo, el chantre Juan de Melgarejo - «familiar» y persona cercana al prelado- en su declaración en el pleito Tabera-Fonseca afirma que hera muy letrado utriusque iuris doctor (op. cit., $\mathrm{f}^{\mathrm{o}}$ 1065). Dado que en los registros de grados jurídicos de este estudio (GHEZZO, P.M.: Acta academicorum gymnasii Patavini ab anno 1451 ad annum 1460. Padova, 1990) no puede hallarse rastro alguno de Don Alonso, es razonable intuir su asistencia a otro centro.

"CUADERNOS DE ESTUDIOS GALLEGOS", Tomo XLVII, Fascículo 112, Santiago 2000. 
sas y contradictorias lo sitúan en Sevilla, Salamanca o Italia cuando, en 1460, es designado para la sede compostelana.

Los acontecimientos que suceden a este nombramiento parecen claros en sus líneas maestras, no así en lo referente a los detalles y las razones de fondo ${ }^{8}$ : sabemos queAlonso de Fonseca I, arzobispo de Sevilla, conmutó con permiso regio y pontificio su sede con la de su sobrino, Alonso de Fonseca II, con el fin de facilitarle la posesión de la sede. La razón de esta extraña permuta hay que buscarla en las difíciles circunstancias que en este momento viven la iglesia y la ciudad compostelana, pero también en las vicisitudes del rey Enrique IV y en sus dificultades para encaminar la sucesión. Al tumultuoso mandato del anterior prelado, Rodrigo de Luna, sucede un no menos conflictivo epílogo: la ciudad compostelana rechaza y resiste violentamente al señorío arzobispal, espoleada y apoyada por el Conde de Trastámara. Para poner fin a este asunto cuenta el nuevo arzobispo con el apoyo del rey, de parte de la nobleza gallega -que le auxilia con sus armas-y de la mayoría de su cabildo catedralicio.

En marzo de 1461 las huestes arzobispales ponen cerco a la ciudad, ocupándola a finales de ese año o en los primeros meses del siguiente - gracias en buena medida a la muerte del conde de Trastámara en el verano de ese año-. La vuelta de Alonso de Fonseca I a Sevilla resulta cuestión dificil, ya que su sobrino, apoyado por parte del clero y de la población se resiste a ocupar la sede compostelana. La recomposición de los puestos tiene lugar en 1463, tras largos esfuerzos políticos y pontificios. En diciembre de ese año se data el primer documento de la administración de don Alonso de Fonseca II, si bien su llegada a la ciudad se demora hasta el año siguiente ${ }^{9}$.

${ }^{8}$ LÓPEZ FERREIRO, A.: Historia, v. VII, pp. 241-249; PORTELA PAZOS, S.: Galicia, p. 33-36; ORTIZ DE ZÚÑIGA, Annales, pp. 28-32; GARCÍA ORO, J.: Galicia na Baixa Idade Media. Igrexa, Señorío e Nobreza. (2a ed.) Noia, 1999; pp. 123-124; SANZ FUENTES, M.J.; SIMÓ RODRÍGUEZ, M.I.: Catálogo de los documentos contenidos en los libros de cabildo del concejo de Sevilla. Sevilla, 1975; docs. $\left.\mathrm{n}^{\circ} 727,728,734\right)$; CRÓNICA anónima de Enrique IV de Castilla (1454-1474), ed. de Pilar Sáchez Parra. Madrid, 1991; pp. 134-146.

${ }^{9}$ Así, el 15 de diciembre de ese año, Juan García de Gomara, actuando como provisor - cargo en el que permanecerá hasta su muerte- hace colación de una capellanía en Cacavelos. (AHDS, F.G., Leg. 370,1). Anteriormente, seguramente por designación de su tío ejerce como provisor Juan Arias del Villar (documento del 16-11-1462; editado en VÁZQUEZ BERTOMEU, M.: Actas Capitulares, v. I. (en prensa), $\mathrm{f}^{\mathrm{D}} 292 \mathrm{v}$ ).

"CUADERNOS DE ESTUDIOS GALLEGOS", Tomo XLVII, Fascículo 112, Santiago 2000. 
El nuevo arzobispo hereda una Iglesia cuya autoridad señorial es contestada y que está sumida en una profunda crisis económica e institucional. Por ello, los primeros años de Fonseca en su sede son también los de puesta en marcha de un ambicioso programa de actuación encaminado a un objetivo claro: recuperar el control del señorío arzobispal. Para ello contará con un equipo de personas que trae consigo y que pertenecen a su círculo más íntimo: Luis de Acevedo, su hermano; Juan García de Gomara, que ejercerá como provisor; los futuros canónigos Pedro Maldonado, Gonzalo de Valdivieso, Juan de Barrientos, Pedro deAlmazán y Diego de Castilla -primo del prelado y bisnieto del rey D. Pedro-; y los caballeros Rodrigo Maldonado y Pedro de Ribas, a los que pronto se unirían hidalgos locales como Esteban de Xunqueiras y los Montenegro. La primera acción está directamente encaminada a la recuperación de parte de la autoridad jurisdiccional y militar: con la creación del oficio de alcalde mayor, conferido a Rodrigo Maldonado, socava también la posición del caballero más importante y peligroso de la Tierra de Santiago, Bernal Yáñez de Moscoso, pertiguero mayor de la Iglesia compostelana y siempre preparado para minar la autoridad arzobispal. También en estos primeros momentos aparece Don Alonso como participante activo en la política castellana $^{10}$.

Si bien es necesario no perder nunca la perspectiva de los acontecimientos castellanos y su repercusión en Galicia, este nombramiento, con la merma de atribuciones que supone para el pertiguero, es la causa fundamental del primer conflicto del arzobispo Fonseca y, muy posiblemente, contribuye a oscurecer sus relaciones futuras con el linaje de los Moscoso. En una atrevida escaramuza, Bernal Yáñez prende al arzobispo durante una visita de éste a la villa de Noia, reteniéndole en cautividad aproximadamente dos años. Resulta imposible, por el momento, establecer la cronología de este acontecimiento que debe tener lugar a finales de 1464 o en los primeros meses del año siguiente, ya que el primero de marzo de 1465 el rey Enrique IV da órdenes precisas para procurar la

\footnotetext{
${ }^{10}$ En efecto, durante el año 1464 el arzobispo compostelano secunda los repetidos llamamientos que los prelados del reino hacen al rey en favor de la pacificación (REAL ACADEMIA DE LA HISTORIA: Memorias de Don Enrique IV de Castilla. Madrid, 1835-1913; v. II, pp. 327-335, 368).
}

"CUADERNOS DE ESTUDIOS GALLEGOS", Tomo XLVII, Fascículo 112, Santiago 2000. 
liberación del prelado. La liberación tiene lugar en los primeros días de 1467 , merced a una concordia ${ }^{11}$. No obstante, los alcaldes de Santiago correspondientes a 1466 fueron designados -facultad reservada al prelado- y juraron su cargo con normalidad, lo que puede indicar que, aún ausente el prelado, el gobierno de la diócesis y señorío mantiene cierta estabilidad $^{12}$. Durante este período de cautiverio tiene lugar un suceso que muy posiblemente marcará la relación del arzobispo Fonseca con su cabildo: el 21 de julio de 1466, reunidos en sesión capitular, los canónigos son hechos prisioneros por Luis de Acevedo y su madre Catalina de Fonseca $^{13}$; buscan, principalmente el acceso sin restricción al tesoro catedralicio para engrosar con su riqueza el rescate de 500 doblas de oro que debe pagarse por la libertad del prelado. Entre los testigos, y posiblemente como participantes, se encuentran algunos canónigos y Rodrigo Maldonado, alcalde mayor ${ }^{14}$. Los acontecimientos se precipitan: la catedral es cercada por Bernal Yáñez, los defensores fonsecanos la fortifican, los beneficiados permanecerán cautivos durante cinco meses, la ciudad y el ejército atacante son excomulgados, .... Finalmente, y tras la muerte de Bernal Yáñez, se llega a un acuerdo -muy duro en sus condiciones para los fonsecanos- que pone fin al conflicto, pactándose la liberación de los canónigos y del prelado -que deberá exiliarse de su diócesis durante diez años ${ }^{15}$.

Parece que, inicialmente, Don Alonso se asienta en la villa de Redondela-de señorío compostelano pero en la diócesis tudense-. Desde allí, el 27 de marzo de 1467 restringe drásticamente los poderes de su obispo auxiliar y de su provisor ${ }^{16}$. La consecuencia más inmediata de este acto es la suspensión de toda colación y provisión beneficial y de todos los proce-

${ }^{11}$ Sobre todos estos acontecimientos: APONTE, Vasco de: Recuento, párr. 205; LÓPEZ FERREIRO, A.: Historia, v. VII, pp. 249-255; PORTELA PAZOS, S.: Galicia, pp. $37-40$.

${ }^{12}$ VÁZQUEZ BERTOMEU, M.: Actas Capitulares, v. I. fo $5 \mathrm{v}$.

${ }^{13}$ op. cit., $\mathrm{f}^{\mathrm{o}} 12 \mathrm{r}$

${ }^{14}$ op. cit., $\mathrm{f}^{\mathrm{D}} 293 \mathrm{v}$. Se advierte ya en este acontecimiento la existencia en el cabildo de una facción fonsecana conformada por los canónigos que llegaron con el arzobispo.

${ }^{15}$ ver supra nota 11.

${ }^{16}$ VÁZQUEZ BERTOMEU, M.: Actas Capitulares, v. I, $\mathrm{f}^{\mathrm{D}}$ 19r.

"CUADERNOS DE ESTUDIOS GALLEGOS", Tomo XLVII, Fascículo 112, Santiago 2000. 
sos judiciales temporales y espirituales de carácter especial de la archidiócesis ${ }^{17}$.

Apenas existen noticias sobre la vida de este personaje durante el conflictivo período Irmandiño ${ }^{18} \mathrm{y}$, aunque cabe suponer que participaría junto a su tío, el arzobispo sevillano, en los acontecimientos políticos de la corona castellana, parece que pasa largas temporadas en Portugal, donde mantiene contactos con otros agraviados del movimiento ${ }^{19}$. Sí sabemos, sin embargo, que sus partidarios capitulares se ausentaron de Santiago ${ }^{20}$. No obstante, no parece existir un vacío de poder, al menos en su aspecto

${ }^{17}$ Todo ello podría interpretarse como una vuelta al prelado de atribuciones temporalmente cedidas a causa de su incapacidad para ejercerlas directamente. Sin embargo, tanto el provisor como el obispo de Sebastia -que actúa como auxiliar- recuperarán estas competencias a partir de 1470, lo que induce a creer que la delegación es algo habitual en el procedimiento de la administración diocesana y que la concentración de las prerrogativas en manos del prelado tiene como finalidad hacer sentir su presencia aún permaneciendo fuera de su capital.

${ }^{18}$ Cabe pensar que parte de esta época la pasa en Salamanca. En esta ciudad, ya desde 1463-64 existe un amplio movimiento de oposición al rey Enrique encabezado por el llamado bando de San Benito -al que pertenecen los Fonseca-; este grupo se mantendrá políticamente activo en defensa de los intereses del infante Don Alonso y después de Doña Isabel, hasta que ésta se consolida como soberana castellana (LÓPEZ BENITO, I.: Bandos, p. 66 y ss.). Sobre la hermandad, sus antecedentes, desarrollo y consecuencias ver especialmente ANDRADE CERNADAS, J.M.; PÉREZ RODRÍGUEZ, F.J.: Historia de Galicia. Galicia medieval. Oleiros, 1995; pp. 267-294 y LÓPEZ CARREIRA, A.: Os Irmandiños. Vigo, $2^{\mathrm{a}}$ ed. 1992; RODRÍGUEZ GONZÁLEZ, A.: Las fortalezas, passim.

${ }^{19}$ En la localidad fronteriza de Monção otorga una carta (31-08-1468) al cabildo de Ourense relacionada con la elección de un nuevo prelado (LÓPEZ FERREIRO, A.: $G a$ licia, pp. 32-33). En esta zona lo sitúan también algunos testigos del Pleito Tabera-Fonseca (RODRÍGUEZ GONZÁLEZ, A.: Las fortalezas, $\left.\mathrm{f}^{\circ} 1059\right)$ y Vasco de Aponte (Recuento, párr. 337-338).

${ }^{20}$ En efecto, Juan García de Gomara, Diego de Castilla, Juan de Barrientos, Pedro Maldonado, Gonzalo de Valdivieso y Roy Fernandez de Lugo se ausentaron durante este periodo (VÁZQUEZ BERTOMEU, M.: Actas Capitulares, v. I, fo 81 r). Este hecho quizás se deba más a un deseo de permanecer con el prelado o al temor, que a una verdadera escisión capitular o expulsión. En febrero de 1468, se une a ellos Gómez Ballo, para el cual solicita el prelado que sea considerado como su familiar (resulta, cuando menos sorprendente, que la carta arzobispal sea presentada en cabildo por Antonio Yans y Juan Núñez Vinagre, regidor y significado miembro de la Hermandad compostelana). Sobre el comportamiento del cabildo compostelano respecto a estos sucesos vd. VÁZQUEZ BERTOMEU, M.: La institución notarial y el cabildo compostelano (1460-1481). Santiago de Compostela, 1996; v. I, pp. 31-36.

"CUADERNOS DE ESTUDIOS GALLEGOS", Tomo XLVII, Fascículo 112, Santiago 2000. 
político, ya que durante estos años los alcaldes compostelanos son renovados anualmente y hacen su juramento al cabildo con normalidad ${ }^{21}$; se nota, no obstante, un cierto desorden dentro del cuerpo clerical ${ }^{22}$. Las noticias existentes confirman la existencia de una relación al menos correcta entre prelado y cabildo: se aprueba su solicitud de familiaridad en favor de Gómez Ballo y la designación que hace de un colegial para el colegio boloñés de San Clemente ${ }^{23}$.

La primera noticia de la vuelta del prelado la proporciona la documentación capitular. El dos de abril de 1469, la asamblea de canónigos expresa su más rotundo rechazo a cualquier enfeudación, censo o alienación que el prelado realice o haya realizado sobre los bienes de su mesa arzobispal ${ }^{24}$, claro indicio de movimientos y dádivas que buscan apoyos y la formación de un ejército. El tesorero y provisor Juan García de Gomara asiste ya a la reunión capitular del 3 de agosto de ese año ${ }^{25}$. El proceso de recuperación del señorío es, sin embargo, lento y laborioso ${ }^{26}$ y se hace necesario pactar la entrada del contingente arzobispal en Santiago. El cerco, que dura casi un $a_{n ̃ o}{ }^{27}$, finaliza con el juramento arzobispal de respetar los privilegios, usos y costumbres de la ciudad. No consta, quizás por ello, la existencia una política de represión del arzobispo hacia aquellos que se levantaron contra él ${ }^{28}$.

${ }^{21}$ VÁZQUEZ BERTOMEU, M.: Actas Capitulares, v. I, fo 14v, 75r.

${ }^{22}$ En efecto, el 3 de octubre de 1468, ante la inexistencia de una autoridad eclesiástica definida, el cabildo -recuperando temporalmente su función de cotitular de la Iglesià Compostelana- encomienda a uno de sus miembros la creación de una cárcel eclesiástica (VÁZQUEZ BERTOMEU, M.: Actas Capitulares, v. I, $\mathrm{f}^{\mathrm{D}}$ 66r).

${ }^{23}$ Ibidem, $\mathrm{f}^{\mathrm{o}} 39 \mathrm{r}, 45 \mathrm{r}$.

${ }^{24}$ Ibidem, $f^{\mathrm{o}} 76 \mathrm{v}$. En principio, este consentimiento capitular sólo es necesario para las enajenaciones absolutas del patrimonio eclesiástico por lo que esta declaración capitular debería entenderse en este estricto sentido.

${ }^{25}$ Ibidem, $\mathrm{f}^{\mathrm{0}} 76 \mathrm{r}$.

${ }^{26}$ Una descripción muy minuciosa de los acontecimientos del retorno señorial en LÓPEZ FERREIRO, A.: Galicia, pp. 45-50.

${ }^{27}$ Véase sobre todos estos acontecimientos la declaración del chantre Juan de Melgarejo en el pleito Tabera-Fonseca (RODRÍGUEZ GONZÁLEZ, A.: Las fortalezas, $\mathrm{f}^{\mathrm{o}}$ $1057 \mathrm{v}-1068 \mathrm{r}$.).

${ }^{28}$ Los testigos del Pleito Tabera-Fonseca coinciden en declarar que el arzobispo no intenta -salvo en contadas excepciones- resarcirse de sus daños a costa de los vecinos. De hecho, en la documentación de los años siguientes, es posible encontrar a alguno de 
La década de los setenta se caracteriza, en el territorio compostelano, por la sucesión de conflictos nobiliarios de carácter militar tras los que subyacen, en muchas ocasiones, las tensiones políticas que en este momento se viven en el reino castellano; hay que tener en cuenta también, la necesidad que tienen los grandes caballeros de recomponer su espacio y de buscar un equilibrio de fuerzas que permita la reconstrucción y la coexistencia pacífica de sus señoríos. En la Tierra de Santiago estos procesos serán especialmente dificultosos al coexistir intereses y personajes dispares: el arzobispo Fonseca -que pretende hacer del señorío arzobispal compostelano una entidad hegemónica-, Pedro Álvarez de Sotomayor -interesado en expandirse desde el territorio tudense hacia el norte, con los ojos puestos en Pontevedra-y Lope Sánchez de Moscoso -joven heredero de la casa de Altamira, necesitado de recomponer su señorío y obtener el poder efectivo sobre él-, sin olvidar a personajes de relevancia menor en los acontecimientos generales, pero de gran peso político tanto en el espacio compostelano como en Galicia-Suero Gómez de Sotomayor o Gomez Pérez das Mariñas. Los principales aliados de Fonseca serán Pedro Álvarez Osorio, conde de Lemos, y Sancho de Ulloa, hermano del canónigo compostelano Gonzalo de Ulloa y de María de Ulloa -amante del prelado-.

Inmediatamente, el prelado reinicia su política de recuperar el control efectivo del señorío compostelano ${ }^{29}$. Para conseguir este objetivo y, especialmente, impedir la reconstrucción de las fortalezas nobiliarias de la Tierra de Santiago, el arzobispo Fonseca se ve inmerso en constantes enfrentamientos militares. Sus principales adversarios serán Lope Sánchez

\footnotetext{
los cabecillas irmandiños de la ciudad compostelana ejerciendo como regidores o alcaldes concejiles (puestos de nombramiento arzobispal); por citar dos casos muy señalados, los regidores Juan Núñez Vinagre -diputado de la Hermandad- y Álvaro García Chantreiro, continúan en los años siguientes ocupando su puesto en el concejo y no es dificil encontrarles en la documentación de la época, incluso relacionándose con el cabildo o el propio prelado. Por ejemplo, Juan Núñez precibe hacia 1471 -en calidad de tutor de Gómez Ballo- una parte de las rentas devengadas por las alcabalas del vino y el pescado de la ciudad de Santiago (ACS, Leg. 699 C, fo 110r-110v); Álvaro García Chantreiro recibe en 1471 el cargo de alcalde concejil-de nombramiento arzobispal-(VÁZQUEZ BERTOMEU, M.: Actas Capitulares, v. I, fo 93r).

${ }^{29}$ Según Vasco de Aponte, Fonseca tardó menos de un año en iniciar las maniobras contra el señor de Altamira (Recuento, párr. 213).
} 
de Moscoso -señor de Altamira-y Pedro Álvarez de Sotomayor, que son secundados en muchas ocasiones por otros miembros de la nobleza gallega. Frente a sus adversarios, establece ligas y confederaciones, según dictan las circunstancias, con el Conde de Lemos, con el de Monterrey o con el adelantado mayor de Galicia, Fernando Pareja, ${ }^{30}$ y establece un dispositivo militar constante. Su hermano, Luis de Acevedo, aparece como el jefe de los ejércitos arzobispales, siendo secundado por hidalgos afectos a la causa fonsecana y algunos otros miembros de la «familia» arzobispal ${ }^{31}$. En varias ocasiones citan las fuentes la presencia personal del prelado en estos combates ${ }^{32}$.

Estos enfrentamientos alcanzan su punto álgido entre 1472-74 cuando buena parte de las villas del señorío arzobispal -y un incierto número de feligresías y fortalezas- están ocupadas por Lope Sánchez de Moscoso o Pedro Álvarez de Sotomayor ${ }^{33}$. En este último año, el prelado pone en práctica una nueva estrategia para encontrar solución a sus problemas. Para frenar la expansión de Pedro Álvarez de Sotomayor primero pacta con é ${ }^{34} \mathrm{y}$ posteriormente lleva a cabo una coalición con Diego de Muros, obispo de Tui ${ }^{35}$. Concierta también dos matrimonios singulares, que buscan pacificar el frente norte de su señorío: Luis deAcevedo -su hermanocon Ginebra das Mariñas y Lope Sánchez de Moscoso con su hermana Aldonza; sobre las condiciones de estos esponsales existen noticias diversas, si bien está claro que Luis deAcevedo recibe en feudo la fortale-

\footnotetext{
${ }^{30}$ Toda esta sucesión de acontecimientos ha sido relatada muy pormenorizadamente en diferentes investigaciones: GARCÍA ORO, J.: Galicia na Baixa Idade Media, pp. 131-136; LÓPEZ FERREIRO, A.: Galicia, pp. 59-73; LÓPEZ FERREIRO, A.: Historia, v. VII, pp. 261 y ss.; PORTELA PAZOS, S.: Galicia, pp. 76-88.

${ }^{31}$ Vasco de Aponte refiere la presencia de personajes de las familias Fonseca, Acevedo y Maldonado en alguna escaramuza (Recuento, párr. 215, 220).

${ }^{32}$ Así, ocurre en la batalla de Ponte Maceira (Recuento, párr. 223 y ss.).

${ }^{33}$ Ver supra nota 30.

${ }^{34}$ Documento publicado por GARCÍA ORO, J.: Galicia na Baixa Idade Media, pp. 297-299.

${ }^{35}$ Documento otorgado el 10 de abril de 1474 (publicado por LÓPEZ FERREIRO, A.: Historia, v. VII, ap. XXXIX, pp. 142-144). Fruto de este acuerdo es también la concesión a Diego de Muros, sobrino del obispo de Tui, de una canonjía en la Iglesia compostelana (VÁZQUEZ BERTOMEU, M.: Actas Capitulares, v. I, $\mathrm{f}^{\circ}$ 160r). Una valoración de estos acontecimientos en GARCÍA ORO, J.: Galicia en los siglos XIV y XV, v. I, pp. 318-319.
}

"CUADERNOS DE ESTUdiOS GALLEGOS", Tomo XLVII, Fascículo 112, Santiago 2000. 
za de Mesía y Lope Sánchez de Moscoso 300.000 maravedíes como dote de su esposa, a la que se une la cesión temporal de la fortaleza de $\mathrm{Cira}^{36}$. También en la corte se emprenden acciones y el arzobispo consigue varias provisiones reales urgiendo a sus oponentes a devolver los bienes usurpados ${ }^{37}$.

Este último hecho se relaciona ya con la actitud de Fonseca respecto a la sucesión en el trono castellano ${ }^{38}$. Partidario decidido de la causa isabelina, el prelado centra sus esfuerzos diplomáticos y bélicos contra Pedro Álvarez de Sotomayor: renueva el pacto con Diego de $\operatorname{Muros}^{39}$ y visita la corte en la primavera de $1475^{40}$. A su alrededor se concentrarán los esfuerzos de este partido en Galicia, amenazada por las tropas portuguesas. La ciudad de Pontevedra, ocupada por las tropas de Pedro Álvarez de Sotomayor, resiste los sucesivos cercos impuestos por el ejército arzobispal hasta el verano de 1477, tras ella, Redondela y Vigo pasarán nuevamente a manos arzobispales ${ }^{41}$. Posiblemente, poco después, el arzobispo necesitará nuevamente concentrar sus esfuerzos contra el señor de Altamira, que le ocupa la fortaleza del Pico Sacro, en las proximidades de Santiago ${ }^{42}$.

\footnotetext{
${ }^{36}$ Con estos tratos, el prelado busca, sin duda, poner fin a la cuestión existente con Moscoso sobre la posesión de ambas fortalezas.(VÁZQUEZ BERTOMEU, M.: «El libro memorial de pleitos del arzobispo don Alonso de Fonseca III» en Compostellanum (1999), en prensa, $\mathrm{f}^{\mathrm{0}} 3 \mathrm{r}$; Archivo Histórico Diocesano de Santiago (AHDS), Fondo General, Leg. $\left.501,4, \mathrm{f}^{\mathrm{o}} 13 \mathrm{r}, 25 \mathrm{r}\right)$.

${ }^{37}$ Así, a Pedro Álvarez de Sotomayor, a Lope Sánchez de Moscoso y a Suero Gómez de Sotomayor se les urge para que restituyan al arzobispo la villa de Padrón que, indebidamente, le tenían ocupada y levantasen el cerco puesto a su iglesia (AGS, RGS, 147503-05, fo 264). A Lope Sánchez de Moscoso para que entregue al prelado las villas de Muxía y Malpica y la fortaleza de Cira (AGS, RGS, 1475-03-06, fo 343). A Pedro Álvarez de Sotomayor para que devuelva las villas de Pontevedra, Vigo y Redondela que tenía indebidamente ocupadas (AGS, RGS, 1475-03-06, $\mathrm{f}^{\mathrm{0}} 266$ ).

${ }^{38}$ Sintéticamente, pero de modo muy claro, sobre los acontecimientos de la guerra civil en Galicia ver ANDRADE CERNADAS, J.; PÉREZ RODRÍGUEZ, F.J.: Galicia, pp. 302-307.

${ }^{39}$ LÓPEZ FERREIRO, A.: Historia, v. VII, p. 282.

${ }^{40}$ Este viaje tiene lugar, seguramente, en abril de 1475 . Ya a principios de año, el cabildo le hace un generoso préstamo (VÁZQUEZ BERTOMEU, M.: Actas Capitulares, v. I. $\left.f^{\circ} 176 \mathrm{v}\right)$ y a principios de marzo se elige la delegación capitular que le acompañará (Ibidem, fo 177r).

${ }^{41}$ LÓPEZ FERREIRO, A.: Historia, v. VII, pp. 283-286.

${ }^{42}$ Ver sobre este asunto, las provisiones reales dadas en abril de 1478 en favor del arzobispo (AGS, RGS, 1478-04-20, fo 77 y AGS, RGS, 1478-04-23, f 72 ).
}

"CUADERNOS DE ESTUDIOS GALLEGOS", Tomo XLVII, Fascículo 112, Santiago 2000. 
Durante estos años, al amparo de los conflictos que ha de afrontar el prelado, los compostelanos, que hacen frente común con las demás villas del señorío arzobispal ${ }^{43}$, conspiran también contra el arzobispo. Existen, asimismo, desencuentros con el cabildo catedralicio, que quizás son reflejo de las divisiones internas de la sociedad compostelana ${ }^{44}$. Todas estas cuestiones sin duda crean, además, importantes problemas en la maltrecha economía arzobispal: enormes gastos en contingentes militares; reconstrucción, construcción y mantenimiento de infraestructuras; imposibilidad de recaudar las rentas corrientes,...

Esta década, a la luz de los acontecimientos brevemente relatados, supone un constante cúmulo de dificultades para el prelado que, sin embargo, consigue ir dando forma a su proyecto: consigue presentarse como el principal apoyo de la corona en Galicia y asienta su nuevo modelo administrativo -plenamente operativo en los ochenta-. Posiblemente, es también el período en el que el prelado reside con mayor continuidad en su iglesia, a tenor de su intensa relación con los acontecimientos.

En el aspecto personal, la vida del prelado es también objeto de cambios. Su madre, Catalina de Fonseca, que le acompañó a Santiago y constituyó un firme apoyo de su causa en los momentos más difíciles, fallece en Salamanca en los primeros meses de $1470^{45}$. Por otra parte, de su relación con doña María de Ulloa nacen entre 1470 y 1476 sus dos hijos, Diego y Alonso ${ }^{46}$. A medida que pasan estos años, diferentes miembros de las familias Fonseca, Acevedo, Maldonado y Castilla - profundamente emparentados entre ellos e íntimamente relacionados con el arzobispo-co-

${ }^{43}$ GARCÍA ORO, J.: Galicia en los siglos XIV y XV, v. II, pp. 58-59, 178-179.

${ }^{44}$ VÁZQUEZ BERTOMEU, M.: Actas Capitulares, vol. I, $\mathrm{f}^{\mathrm{D}} 179 \mathrm{r}, 189 \mathrm{v}$.

${ }^{45}$ Sobre ella ver VÁZQUEZ BERTOMEU, M.: Actas Capitulares, v. I, fo 12r, 290r, $293 \mathrm{v}$; acerca del funeral celebrado por su alma en la basílica compostelana. Archivo de la Catedral de Santiago, Cofradía de la Concepción, Libro 1, fo 152r (05-04-1470).

${ }^{46}$ En CAAMAÑO BOURNACELL, J.: Notas para un estudio sobre la verdadera personalidad de doña María de Ulloa, madre del arzobispo don Alonso de Fonseca III. Coruña, 1950, se encontrarán interesantes datos sobre esta mujer, viuda de Alvaro Páez de Sotomayor. Resulta imposible, por el momento, establecer con fiabilidad las fechas y lugares de nacimiento de sus hijos, aunque tradicionalmente se considera que el menor de ellos, Alonso, nace en 1476. En 1480, Diego -denominado hijo de Álvaro de Sotomayor- es prohijado por su tío Pedro de Acevedo (RAH, Colección Salazar y Castro, $\mathrm{n}^{\circ}$ 52.994).

"CUADERnOS DE ESTUdios GALLEGOS", Tomo XLVII, Fascículo 112, Santiago 2000. 
mienzan a escalar puestos en los asuntos de estado en un preludio de la influencia que alcanzarán en tiempos venideros ${ }^{47}$.

Parte de los problemas en Santiago entran en vías de solución a partir de 1480 con el asentamiento definitivo de la administración real en Galicia, aunque surgirán otros de diferente cariz. El establecimiento de la Hermandad, que tiene lugar a partir de este año, constituye un hecho fundamental ya que proporciona una fuerza militar de apoyo a los agentes reales. Posiblemente temiendo esta circunstancia y recordando las peligrosas derivaciones de la Hermandad anterior, los grandes caballeros gallegos resistieron la implantación de esta organización ${ }^{48}$. Alonso de Fonseca, seguro de la baza política que ello supone, acepta y promulga con rapidez la hermandad en su señorío ${ }^{49}$. No cuenta, sin embargo, con los objetivos a largo plazo de la corona ni con la eficiencia de su más reciente delegado, Fernando de Acuña ${ }^{50}$.

En efecto, en su misión de fortalecer la presencia real en Galicia el nuevo gobernador Acuña, apoyándonse en un ejército propio, en la recién creada Hermandad, en ocasiones también en los caballeros gallegos y en sus amplios poderes, está firmemente decidido a socavar en ciertos aspectos la poderosa posición del prelado en beneficio del orden público y de la corona: las quejas de las ciudades y villas del señorío - constantes desde los años 70-encontrarán mayor eco y las fortalezas arzobispales pasarán a manos del gobernador. Surgen, por ello, los primeros desencuentros

${ }^{47}$ Sobre este tema, si bien estudiado desde otra perspectiva ver SAGARRA GAMAZO, A.: Burgos y el gobierno indiano: la clientela del Obispo Fonseca. Burgos, 1998; pp. 53-56; acerca del entramado familiar SAGARRA GAMAZO, A.: La familia Fonseca, passim.

${ }^{48}$ Sobre ello ver GARCÍA ORO, J.: Galicia na baixa Idade Media, pp. 151 y ss. y 300-304; y especialmente Galicia en los siglos XIVy XV, v. I, pp. 331-340. Quizás habría que tener en cuenta también, a la hora de valorar este comportamiento nobiliario, la vertiente económica de la hermandad, a la que contribuyen hidalgos y pecheros, que puede haber constituido una amenaza a los ya maltrechos ingresos señoriales. Sobre este aspecto de la hermandad ver LADERO QUESADA, M.A.: La Hacienda real de Castilla en el siglo XV. La Laguna, 1973; pp. 214-217.

${ }^{49}$ GARCÍA ORO, J.: Galicia en los s. XIV y XV, v. I, p. 334

${ }^{50}$ Sobre la actuación de Fernando de Acuña ver GARCÍA ORO, J.: Galicia en los siglos XIV y XV. v. I, pp. 341-351; FERNÁNDEZ VEGA, L.: La Real Audiencia de Galicia. Órgano de gobierno en el Antiguo Régimen (1480-1808). Coruña, 1982; v. III, pp. 134-141.

"CUADERNOS DE ESTUDIOS GALLEGOS", Tomo XLVII, Fascículo 112, Santiago 2000. 
entre el prelado y el gobernador a los que se unirán otros que tienen su origen en las competencias jurisdiccionales y en la fiscalidad arzobispal.

A tenor de las informaciones de las que disponemos permanecen, además, abiertos algunos conflictos del período anterior: la querella con Pedro Álvarez de Sotomayor sobre las rentas y bienes arzobispales en el sur del señorío ${ }^{51}$, los problemas con Lope Sánchez de Moscoso ${ }^{52}$, el descontento de los compostelanos ${ }^{53} \mathrm{o}$ la abierta rebelión fiscal ${ }^{54}$.

Para la comprensión de la evolución de estos procesos y de los acontecimientos sucedidos en los años siguientes es necesario tener en cuenta que, desde 1481, Don Alonso reside cada vez menos en su diócesis. Por ello, la resolución inmediata de los problemas cae en manos de sus agentes, personas de gran capacidad pero imposibilitadas para tomar decisiones de gran alcance, que siempre permanecerán en manos del prelado. En efecto, desde que, en febrero de 1481, Fonseca es nombrado presidente del Consejo Real su alejamiento de los asuntos gallegos es patente, aunque no ocurre lo mismo con sus objetivos respecto a la Iglesia compostelana, ni con la alta eficacia de sus influencias, ya que sus allegados y el gran apoyo de los reyes a su posición evitan a la Iglesia compostelana y a su señorío la entrada en crisis.

${ }^{51}$ Sobre ello, el 7 de marzo de 1480, los reyes despacharon una provisión conminando al prelado a entregar a Don Pedro la zona del Morrazo y ciertas feligresías en cerca de Pontevedra -según lo acordado en la paz con Portugal-, (AGS, RGS, 1480-III, f ${ }^{\circ} 343$ ). En este mismo mes, se otorgan otros documentos, esta vez en favor del arzobispo, intimando a Sotomayor a devolver a Fonseca lo que le pertenece (AGS, RGS, 1480-III, f $203,237,379,388$ ).

${ }_{52}$ Un libro de rentas arzobispales de estos años registra referencias a movimientos militares y al conflicto con el conde de Altamira sobre una deuda pendiente a causa de una sentencia sobre el puerto de Fisterra y sobre las feligresías de Bora y Mourente (ACS, Libros de la Recabdança, Cuaderno $2^{\circ}, f^{\circ} 5 r, 14 v$ ). Indudablemente, el matrimonio de Moscoso con la hermana de Fonseca no consigue la alianza buscada (APONTE, V.: Recuento, párr. 242, 278).

${ }^{53}$ Vasco da Ponte refiere claramente la predominante posición de Sancho de Ulloa, conde de Monterrey, en la ciudad durante los primeros años 80 (Recuento, $\mathrm{f}^{\mathrm{o}} 270$ ).

${ }^{54} \mathrm{~A}$ las dificultades que suponen las denuncias de arbitrariedad realizadas por las villas en los años 70 (GARCÍA ORO, J.: Galicia en los siglos XIV y XV. v. I, pp. 341-343) se une ahora una expeditiva actuación de los recaudadores reales en Galicia, que impedirán al prelado el cobro de parte de las alcabalas; a ello se unen claras resistencias populares al pago de otras rentas debidas al prelado (ACS, Libro de Recabdança, Cuaderno 1, passim).

"CUADERNOS DE ESTUDIOS GALLEGOS", Tomo XLVII, Fascículo 112, Santiago 2000. 
El definitivo asentamiento de la autoridad y administración real en Galicia se manifiesta como factor decisivo de estabilidad, especialmente al dotar a la sociedad de un órgano donde dirimir los conflictos (el tribunal real del que nacerá la Real Audiencia de Galicia). El alejamiento de los contingentes armados nobiliarios y el acercamiento de los grandes caballeros a las tareas cortesanas contribuye decisivamente a la pacificación del reino, al fortalecer sus bases económicas y prestigio personal y social y quedar la administración señorial en manos de agentes ejecutores. El relevo del gobernador Acuña por Diego López de Haro (eficiente pero más diplomático), la visita de los reyes a Galicia en 1486, su política posterior y el definitivo asentamiento de la Real Audiencia son definitivos elementos a tener en cuenta en este proceso.

Las consecuencias más inmediatas de este cúmulo de circunstancias son: un cierto fortalecimiento de la posición arzobispal respecto al gobernador Acuña, consiguiendo la devolución - por orden real- de la fortificación catedralicia y la amnistía para sus allegados. La ausencia del prelado de Galicia -a la que seguirá pronto la de los más importantes nobles gallegos, que serán encaminados a la empresa granadina- rebaja las tensiones y los enfrentamientos, cuyo perfil será más bajo, ya que serán escaramuzas y conflictos de carácter local y puntual protagonizados por los correspondientes agentes administrativos.

En efecto, dado que a partir de 1485 las visitas de Fonseca a Santiago son esporádicas, el gobierno de la iglesia y señorío queda en manos de sus allegados. En esta tesitura, los cargos de provisor, alcalde mayor y recaudador son proveídos en personas de su más estricta confianza y, aunque cada uno de ellos parece tener un cometido específico, son muchos los indicios que apuntan a un grupo compacto que gobierna de modo global ${ }^{55}$. La larga duración del mandato de este prelado le permite también acabar -de modo progresivo y sin grandes estridencias- con las resistencias existentes en los dos órganos colegiados más cercanos: el cabildo y el

${ }^{55}$ Son muchos los documentos en los que aparecen estos tres cargos uniendo fuerzas respecto a un tema (AHDS, Fondo General, Leg. 501, 2, $\mathrm{f}^{\circ} 18 \mathrm{r}$; Ibidem, Leg. $70 \mathrm{~A}, \mathrm{f}^{\circ}$ 56v-58r; Ibidem, Leg. 70, Carp. 2, $\mathrm{f}^{\mathrm{0}} 2 \mathrm{v}$ ). Las cuentas del recaudador Nicolás de Acevedo refieren explícitamente, en varias ocasiones, actuaciones realizadas con el consejo del alcalde mayor o del provisor (Libro de Recabdança, Cuaderno 2, fo 4r, 7r, 18r).

"CUADERNOS DE ESTUDIOS GALLEGOS", Tomo XLVII, Fascículo 112, Santiago 2000. 
concejo compostelano verán entrar en sus filas a personajes próximos al arzobispo $^{56}$.

No obstante, la sombra de Don Alonso está siempre presente en su Iglesia y señorío, ya sea a través de sus mandatos o de sus visitas a la ciudad $^{57}$, que durante los primeros años de su estancia en la corte posiblemente se desarrollan con cierta asiduidad. Alejado de Galicia, el arzobispo fija su residencia estable en Salamanca, en la casa que fue de su padre y ahora pertenece a su hermano Luis de Acevedo y posteriormente a su homónimo hijo ${ }^{58}$.

Desde 1484, año en el que Don Alonso es nombrado presidente de la Chancillería de Valladolid, muy posiblemente las visitas a Compostela se reducen considerablemente. De hecho, y a lo largo de esta década y hasta 1493 en que tenemos noticia precisa de su regreso a Santiago, son escasas las informaciones sobre la vida del prelado ${ }^{59}$. Durante algún tiempo vive de modo fijo o esporádico en Valladolid, donde preside la Real Chancillería, aunque su lugar de referencia sigue siendo Salamanca. La estancia al frente de tribunal vallisoletano no se desarrolla tampoco dentro de unos cauces totalmente pacíficos, siendo el incidente más sobresaliente el que le relaciona con el proceso sobre el nombramiento de rector del estudio de la ciudad y que enfrenta a la universidad con el corregidor Juan de Ayala ${ }^{60}$. Su gestión como presidente del tribunal, a pesar de los

${ }^{56}$ En efecto, en los volúmenes de actas capitulares correspondientes al mandato de este arzobispo puede apreciarse claramente una creciente presencia de beneficiados pertenecientes a las familias Fonseca, Acevedo, Maldonado, así como de personajes que por familia u oficio se vinculan al prelado. En el caso del concejo, la escasa documentación conservada impide un mayor seguimiento de este fenómeno, sin embargo, en la primera década del siglo siguiente es evidente la identificación de personajes fonsecanos como Antón Maldonado, Francisco Ribas.

${ }^{57}$ No hay que olvidar tampoco que aquí residen doña María de Ulloa y sus dos hijos (ACS, Libro de la Recandabça, Cuaderno 1, $\mathrm{f}^{\mathrm{o}}$ 13r, 23r, 25r, 33v, 34v, 35v; Cuaderno 2: $\left.\mathrm{f}^{\mathrm{o}} 2 \mathrm{r}, 6 \mathrm{r}, 21 \mathrm{r}, 21 \mathrm{v}\right)$

${ }^{58}$ LÓPEZ BENITO, C.I.: La nobleza, p. 61

${ }^{59}$ De hecho, la documentación salmantina de las últimas décadas del siglo XV recoge, con mucha frecuencia, noticias sobre la intervención de familiares y criados del arzobispo en la conflictiva vida política local, pero las menciones explícitas a su presencia en la ciudad son muy escasas (LÓPEZ BENITO, C.I.: Bandos, p. 65-99).

${ }^{60}$ Sobre este conflicto y la intervención del prelado: BELTRÁN DE HEREDIA, V.: Cartulario de la Universidad de Salamanca. Salamanca, 1970-73; v. V, pp. 155-156. 
grandes poderes que le fueron concedidos, no se concreta en una labor reformadora ${ }^{61}$.

Mientras, en Santiago, los representantes arzobispales prosiguen su tarea en persecución de los objetivos fijados por el prelado, especialmente en aquellos asuntos de índole económica y en ocasiones parecen utilizar los mismos métodos expeditivos que su patrón ${ }^{62}$.

A pesar de la contrariedad que supone para DonAlonso la perentoria orden de abandonar Galicia ${ }^{63}$, el prelado parte sin demora para Castilla, donde dedica sus esfuerzos al servicio de la Corona. Los reyes, conscientes de la necesidad de moderar el poder del señorío arzobispal, emplean una estrategia de tira y afloja para poner fin a las disputas entre el gobernador y los agentes arzobispales; de este modo, y sin dañar de manera definitiva la posición del prelado, van asentado la presencia real y poniendo coto al ejercicio abusivo de competencias por parte de la administracion compostelana. El comportamiento de Don Alonso y sus agentes ante las frecuentes disputas con los responsables de la gobernación real en Galicia se limita a escaramuzas militares de bajo perfil, a las reclamaciones en la corte y a la iniciacion de los correspondientes procesos judiciales. Esta nueva estrategia no supone, en modo alguno, un abandono del objetivo final y cada maniobra de los agentes reales da

${ }^{61}$ El documento de nombramiento le concede un amplio margen de acción con vistas a una profunda renovación de la institución (VARONA GARCÍA, A.: La chancillería de Valladolid en tiempo de los Reyes Católicos. Valladolid, 1981; pp. 297, 376-378).

${ }^{62}$ ACS, Libros de la Recabdança, C2, passim; AHDS, Fondo General, Leg. 1262, 25; AHDS, Fondo General, Leg. 1262, f $31 \mathrm{r}$ y ss; AHDS, Fondo General, Leg. 93-1, 2, 7; AHDS, Fondo General, 70 A, fo 51r-52v, AHDS, Fondo de San Martín Pinario, Sar, 31, $\mathrm{n}^{\circ} 8$, etc.

${ }^{63}$ El documento real en GARCÍA ORO, J.: Galicia na Baixa Idade Media, pp. 329330. Los indicios confirman que él realmente conoce el alcance y razones de este mandato: Hasta quel dicho rey don Fernando y la reina doña Isabel reinaran dos o tres años que lo echaron deste reino de Galicia, (cfr. declaración del chantre Melgarejo en RODRÍGUEZ GONZÁLEZ, A.: Las fortalezas, fo 1063); Bernardino Llorca opina que el acuerdo tomado por el clero del reino, en la asamblea celebrada en Córdoba en el año 1482, para que los reyes no obliguen a ningún eclesiástico a trasladase a la corte contra su voluntad constituye una clara alusión al caso del arzobispo Fonseca (Bulario pontificio de la Inquisición española en su periodo institucional (1478-1525). Roma, 1949; pp. 90-92).

"CUADERNOS DE ESTUDIOS GALLEGOS", Tomo XLVII, Fascículo 112, Santiago 2000. 
lugar a un documento real extendido a petición del prelado salvaguardando sus intereses ${ }^{64}$.

A pesar de la escasez de referencias documentales es evidente que en estos años la posición de Fonseca en la corte se fortalece de modo considerable, posiblemente no sólo a causa de los servicios prestados -por él y su familia, en Galicia, Salamanca y en la corte-a los Reyes en los difíciles acontecimientos de los tiempos pasados, sino también gracias a sus generosas aportaciones al tesoro real. En efecto, en los años 80 el prelado presta a la Corona importantes cantidades que, tarde o temprano, le serán devueltos en metálico o en mercedes ${ }^{65}$. La más importante de ellas, posiblemente, es la concesión -en principio- a título personal y vitalicio, de las alcabalas de los reguengos de la archidiócesis compostelana ${ }^{66}$-esta renta cobrada tradicionalmente por los arzobispos está embargada desde 1480 -. Además, durante estos años son varias las provisiones reales enviadas a Santiago para que a Fonseca les sean abonadas cantidades que se deben por razón de procesos judiciales o por derecho institucional ${ }^{67}$.

${ }^{64} \mathrm{Asi}$, es frecuente ver a los provisores -Juan García de Gomara y, posteriormente, Fray Gonzalo de Ribera y Rodrigo de Acevedo- actuando con la energía y prontitud que de él se exige en defensa de los intereses arzobispales contra el concejo compostelano en 1484 (ACS, Leg. 436, sin foliar) o ante el de Pontevedra hacia 1489 (AHDS, Fondo General, Leg. 105-4), e incluso contra el gobernador y alcaldes mayores del Reino de Galicia en 1493 (AHDS, Fondo General, Leg. 93-1 y ACS, Leg. 282, 2, f 28r-30r). Del mismo modo actuará su tesorero y recaudador, Francisco de Treviño, primero, y Nicolás de Acevedo, después (ACS, Libros de la Recabdança, passim).

${ }^{65} \mathrm{La}$ contabilidad real registra la existencia de varios préstamos a la corona en 1488 ( 5 millones de maravedíes), 1489 (una cantidad indeterminada de la que sólo se devuelven $1.600 .000 \mathrm{mrs}$ ), 1491 ( 7 millones). En 1489, su hijo, Diego de Acevedo presta 10 millones (LADERO QUESADA, M.A.: La Hacienda, pp. 319-322).

${ }^{66}$ Es necesario recordar los mandatos perentorios a los gobernadores y alcaldes mayores de la audiencia del reino de Galicia que buscan siempre un equilibrio entre ambas partes o las repetidas provisiones otorgadas en los años 80 confirmando el derecho arzobispal al señorío de Santiago o a ciertas rentas que deben sus vasallos (AHDS, FG, Leg. $501,4, f^{\circ} 34 \mathrm{r}$ y ss.). Las alcabalas le fueron concedidas -a tenor del documento real- en gratitud a los gastos y esfuerzos del prelado durante la guerra con Portugal. Al menos desde 1498, le es concedida una renta vitalicia de 300.000 maravedíes anuales (LADERO QUESADA, M.A.: La Hacienda, p. 314).

${ }^{67}$ Así, los reyes otorgan una carta a las justicias de villas y ciudades para que se paguen a don Alonso de Fonseca las rentas que se le deben (AGS, RGS, 1487-VII, $\mathrm{f}^{\mathrm{o}} 37$ ); al gobernador y alcaldes mayores del reino de Galicia, a peticion de Fonseca, para que se

"CUADERNOS DE ESTUDIOS GALLEGOS", Tomo XLVII, Fascículo 112, Santiago 2000. 
Por todo ello, desde 1490 su posición en la corte parece definitivamente ${ }^{68}$ consolidada y, finalizada su labor al frente de la Chancillería de Valladolid, recibe de los Reyes la dignidad de gobernador del reino cuando en 1491 parten hacia la campaña de Granada ${ }^{69}$.

Durante esta última década del siglo, los esfuerzos de Don Alonso se concentran en dos frentes: poner fin a ciertos problemas pendientes en Santiago y preparar el futuro de sus hijos.

En su señorío compostelano dos son los asuntos que le preocupan de un modo más apremiante: el evidente expansionismo de los oficiales de la justicia real y el creciente malestar en las villas. De nuevo la presencia personal del prelado en Santiago (en 1493) provocará una subida en el tono de los conflictos. Los oficiales de la Real Audiencia del reino de Galicia, apoyados sin duda por los concejos de la Tierra de Santiago, comienzan a interferir en las atribuciones de la jurisdicción señorial arzobispal, avocando para sí causas en primera instancia y admitiendo las apelaciones de tribunales locales. Evidentemente la respuesta del arzobispo no se hace esperar y, ya en 1493, los oficiales reales son excomulgados. Se inicia así un nuevo conflicto que se mantendrá hasta bien entrado el siglo XVI, en el que la corona aparece como intermediaria necesaria $-\mathrm{y}$ a veces interesada $-{ }^{70}$. Dada la importancia de la ciudad compostelana, los oficiales de la Real Audiencia residirán en ella con cierta asiduidad, siendo así protagonistas de escaramuzas y conflictos menores que tienen como trasfondo la polémica jurisdiccional y como referente inmediato reyertas callejeras, visitas a la cárcel arzobispal o abusos en los derechos de posada que tienen los miembros de la audien-

cumpla ejecutoria contra el conde de Altamira (AGS, RGS, 1488-I, $\mathrm{f}^{\mathrm{o}} 130$ ); para que el doctor Sancho García del Espinar, alcalde mayor del reino de Galicia, desembargue los frutos y rentas de Lope Sánchez de Moscoso, conde de Altamira, de los cuales habia hecho almoneda el arzobispo de Santiago (AGS, RGS, 1489-II, fo 206).

${ }^{68}$ Por estos años, los Fonseca y Castilla constituyen un grupo que ocupa relevantes puestos en los negocios regios: Sancho de Castilla, Juan de Castilla, Juan Rodríguez de Fonseca, Alonso de Fonseca, obispo de Osma, Antonio de Fonseca y Alonso de Fonseca, señor de Coca y Alaejos.

${ }^{69}$ LÓPEZ FERREIRO, A.: Historia, v. VII, p. 313. Con este movimiento los reyes buscan posiblemente retenerlo en la corte y a la vez gratificarle sus servicios.

${ }^{70}$ FERNÁNDEZ VEGA, L.: loc. cit.

"CUADERNOS DE ESTUDiOS GALLEGOS". Tomo XLVII. Fascículo 112, Santiago 2000. 
cia $^{71}$. En este mismo año de 1493, y a raíz de una violenta discordia sobre la jurisdicción, los alcaldes mayores son excomulgados y el prelado desterrado de la ciudad. Fonseca será de nuevo llamado a la corte y alejado de Galicia si bien la reina acabará reconociendo el abuso de los agentes reales $^{72}$.

En Santiago y demás villas del señorío se aprovecha el malestar existente y la difícil posición arzobispal para retomar las antiguas reivindicaciones que se centran básicamente en dos aspectos: el derecho del prelado a nombrar alcaldes y los pedidos fiscales. En años anteriores, el prelado intentó dominar los concejos por la vía de designar unilateralmente a los alcaldes -contrariamente a la tradición y fueros que refieren la participación de las comunidades por la vía de la designación de una relación de candidatos-, la respuesta no se hace esperar y las villas, especialmente, Santiago y Noia, rechazan los nombramientos y entablan sendos procesos judiciales. La primera sentencia sobre esta cuestión confirmará al prelado el derecho a nombrar alcaldes en Santiago ${ }^{73}$. A este documento seguirán otros $^{74}$.

Las resistencias al pago de tributos al arzobispo existen al menos desde los años 80, sin embargo, se recrudecen entre 1493 y 1497, según los testimonios a causa de las nuevas peticiones del prelado ${ }^{75}$, aunque posiblemente tienen su origen en una mayor eficiencia del sistema recaudatorio arzobispal y en un cambio en la estrategia administrativa. A

\footnotetext{
${ }^{71}$ Como ya se ha dicho, la disputa se mantendrá a lo largo de las dos siguientes décadas; los incidentes más graves tienen lugar durante el mandato de Alonso de Fonseca III, especialmente entre 1509 y 1515 , alcanzando su punto culminante en 1511 con la suspensión de la jurisdicción temporal del arzobispo Alonso de Fonseca III. La documentación se encuentra en AHDS, Fondo General, Leg. 93. Alguno de estos episodios ha sido estudiado por GARCÍA ORO, J.: Galicia en los siglos XIV y XV, v. I, pp. 60-65; y RODRÍGUEZ SUÁREZ, M.P.; VÁZQUEZ BERTOMEU, M.: «Os documentos da serie Cámara-Pueblos do Arquivo Xeral de Simancas referentes a Santiago de Compostela» en Historia Nova I. Contribución dos Xovenes Historiadores de Galicia. Santiago, 1993; pp.167-185.

${ }^{72}$ GARCÍA ORO, J.: Galicia en los siglos XIV y XV., v. II, p. 455-465.

${ }^{73}$ AHDS, Fondo General, Leg. 93-4.

${ }^{74}$ Sobre todo ello ver GARCÍA ORO, J.: Galicia en los siglos XIV y XV, v. II, pp. 178179. LÓPEZ FERREIRO, A.: Fueros, pp. 571-572.

${ }^{75}$ GARCÍA ORO, J.: Galicia en los siglos XIV y XV, v. II, pp. 465-466.
}

"CUADERNOS DE ESTUDIOS GALLEGOS", Tomo XLVII, Fascículo 112, Santiago 2000. 
tenor de las fuentes se trata de un conflicto de largo alcance cronológico y geográfico ${ }^{76}$.

Tras la llamada real para acudir ante los reyes en 1493, Don Alonso posiblemente reside a caballo entre la corte y Salamanca, aunque son escasas las noticias de las que disponemos a este respecto. La documentación salmantina registra la presencia activa de su hijo Diego en la ciudad, hasta su fallecimiento en 1496 y la participación de éste y de otros personajes del ámbito arzobispal en los conflictos de la ciudad durante esta década $^{77}$. Apenas hay noticias sobre su actividad en la corte, donde habrá que suponerle como miembro del consejo real ${ }^{78}$.

Las fuentes muestran también los pasos tomados para encaminar el futuro de sus hijos. A partir de 1490, el prelado o sus agentes, realizan importantes compras de tierras en los alrededores de la ciudad de Salamanca, al objeto de reunir un fondo patrimonial para Don Diego ${ }^{79}$. Se inician también tratos para realizar un matrimonio ventajoso, que cristaliza en 1487 al contraer nupcias con doña Teresa de Zúñiga, hija de Sancho de Ulloa, conde de Monterrey ${ }^{80}$. La prometedora carrera del joven encuentra su fin en 1496, cuando muerre durante el ataque francés a la for-

${ }^{76}$ En efecto, como ya se ha dicho, los primeros testimonios claros apuntan a su existencia hacia 1481 (ACS, Libro de la Recabdança, C1, passim) y se registra tanto en las villas como en los concejos rurales (Ibidem, GARCÍA ORO, J.: loc. cit.).

${ }^{77}$ LÓPEZ BENITO, C.I.: Bandos, pp. 72-93 y 189-190.

${ }^{78}$ La declaración de Juan de Melgarejo - personaje muy cercano al prelado- en el pleito entre los arzobispos Tabera y Fonseca sobre las fortalezas de la Mitra compostelana, informa de la presencia del prelado en Sevilla en 1490 con la corte; y posteriormente en Granada y en Barcelona (RODRÍGUEZ GONZÁLEZ, A.: Las fortalezas, $\mathrm{f}^{\mathrm{0}} 1064$ 1065).

${ }^{79} \mathrm{RAH}, \mathrm{Col}$. Salazar y Castro, $\mathrm{n}^{\circ} 46.721,46.772,53.006-53.010$. Don Alonso concede también a su hijo, antes de 1483 una de las notarías del número de la ciudad de Santiago, que ejerce a través de un sustituto (ACS, Leg. 424-1); es ésta la única presencia del joven en la documentación administrativa compostelana. La cesión de dos notarías de la ciudad en favor de sus hijos, provoca un cierto malestar en la ciudad; a tal punto que los reyes acaban conminándole a entregarlas a personajes que no sean sus familiares, tal y como establecía la legislación que a tal efecto había promulgado Alfonso X (ACS, Leg. $709, \mathrm{f}^{\mathrm{o}} 220 \mathrm{r}$ )

${ }^{80}$ Esta unión, realizada por mandato real y no sin recelos del Conde de Monterrey, lleva consigo la cancelación del contrato de matrimonio entre Teresa de Zúñiga y Alonso Pimentel, hijos de Sancho de Ulloa y Rodrigo Alonso Pimentel, respectivamente. (Archivo Ducal de Alba, C-174-14, C-246-34).

"CUADERNOS DE ESTUDIOS GALLEGOS", Tomo XLVII, Fascículo 112, Santiago 2000. 
taleza de Salsas ${ }^{81}$. Los esfuerzos de Fonseca se centrarán en el futuro en encaminar a su nieto, Alonso deAcevedo y Zúñiga, futuro conde de Monterrey, para el que fundará un mayorazgo en 1504 con los bienes que habían sido de su padre y nuevas adquisiciones ${ }^{82}$.

Menos accidentados resultan los primeros años de la carrera de su otro hijo, Alonso, al que concede una canonjía en Compostela en 1490, el arcedianato de Cornado de esta iglesia en 1496 y una de las notarías de la ciudad $^{83}$. Seguramente por intervención paterna consigue, también en 1492, un beneficio en la iglesia cordobesa, regida a partir de 1499 por su pariente Juan Rodríguez de Fonseca ${ }^{84}$. En estos años, además, tiene lugar un masivo desembarco de personajes cercanos al arzobispo en las filas del cabildo compostelano, buena parte de ellos formarán el equipo de gobierno y la corte de su hijo y sucesor ${ }^{85}$.

${ }^{81}$ BERNÁLDEZ, A.: Historia de los Reyes Católicos Don Fernando y Doña Isabel. Biblioteca de Autores Españoles, Madrid, 1878; cap. CLIII. Sobre las honras fúnebres celebradas por Don Diego en Santiago, en diciembre de 1496, ver ACS, Cofradía de la Concepción, Libro 2, f $\mathrm{f}^{\mathrm{j}}$ 104v-105r. Una semblanza de este personaje, elaborada por Gonzalo Fernández de Oviedo en Batallas y Quinquagenas (ed. de J.B. de Avalle-Arce). Salamanca, 1989; pp. 76-78.

${ }^{82}$ BRAH, Col. Salazar y Castro, $\mathrm{n}^{\circ}$ 52.855-52.856.

${ }^{83}$ ACS, Actas Capitulares, v. II, fo 199v-200r; ACS, Actas Capitulares, v. II, f $\mathrm{f}^{\mathrm{o}} 30 \mathrm{v}$, respectivamente. No se conoce con exactitud la data de concesión de la notaría compostelana al futuro Alonso de Fonseca III, aunque hay que suponer que tiene lugar poco después del fallecimiento del notario Sancho de Cardama que tiene lugar hacia 1482. La concesión de estas notarías a sus hijos suscita una importante resistencia en la ciudad donde dos de los cuatro despachos quedan en manos de factores arzobispales, si bien nunca llegaron a ejercer personalmente. Sobre este asunto ver VÁZQUEZ BERTOMEU, M.: La institución notarial, v. I, pp. 249-250. Nuestro conocimiento de la biografía de este importante prelado es, por el momento, bastante precario; la más completa es, sorprendentemente, la contenida en la monografía sobre el colegio que bajo su patrocinio se construyó en Salamanca (SENDÍN CALABUIG, M.: El colegio mayor del arzobispo Fonseca en Salamanca. Salamanca, 1977; pp. 27-65).

${ }^{84} \mathrm{El}$ disfrute de este beneficio cordobés también da lugar a cierta confusión ya que los datos que hasta el momento se poseen se refieren únicamente a los conflictos surgidos por su posesión (AGS, RGS, 1492-V, fo 518).

${ }^{85}$ En efecto, hacia 1490 pertenecen ya a esta institución Nicolás de Acevedo -sobrino del prelado, tesorero y recaudador mayor en Galicia-, Fernando de Acevedo, Rodrigo de Acevedo -futuro provisor-; a lo largo de la década harán su entrada, entre otros, Alonso de Acevedo, Gonzalo Maldonado, Bernardino de Acevedo, Juan de Acevedo, Joaquín de Auñón o Diego Gutiérrez. (ACS, Actas Capitulares, vols. II y III).

"CUADERNOS DE ESTUDIOS GALLEGOS", Tomo XLVII, Fascículo 112, Santiago 2000. 
De la actividad cortesana del prelado en los últimos años de su mandato compostelano tampoco hay mayores informaciones, aunque es sobradamente conocido el apoyo masivo que su familia ofrece en todo momento al rey Don Fernando. Únicamente consta de modo claro su participación en la comitiva que en 1501 acompaña a la infanta Catalina a Inglaterra ${ }^{86}$.

Sí hay noticia, en cambio, de su permanencia en Salamanca donde nuevamente puede relacionársele con los choques banderizos ${ }^{87}$. Se conoce asimismo su intervención en la disputa que separa al prelado salmantino Juan de Castilla de su cabildo; en este caso, Don Alonso es partidario decidido del bando capitular contra su propio pariente, quien muy probablemente intenta distanciarse de la influencia del compostelano ${ }^{88}$. Los acontecimientos se suceden de tal modo que se hará necesaria la intervención real en 1506, cuando el arzobispo dicta auto de entredicho contra la ciudad y su pastor ${ }^{89}$. Hasta el verano de 1507 , cuando es relevado de la sede compostelana, y aún después con el título de metropolitano, la documentación deja entrever una profunda participación del prelado en la vida ciudadana de Salamanca ${ }^{90}$.

Son precarias también las noticias sobre los acontecimientos sucedidos en tierras compostelanas en estos años, sobre todo a causa de la escasez de documentación. De hecho, los volumenes de actas capitulares constituyen la fuente principal ${ }^{91}$. De su lectura se deduce que, al menos en el

${ }^{86}$ Son varias las crónicas que refieren su presencia en esta expedición, conservándose incluso una de las misivas que como personaje principal de ella envía a la corte castellana (BRAH, Col. Salazar y Castro, $\mathrm{n}^{\circ} 1189$ ).

${ }^{87}$ LÓPEZ BENITO, I.: Bandos, pp. 84-93.

${ }^{88}$ Una valoración de estos acontecimientos, Ibidem, p. 87.

${ }^{89}$ Ibidem y AGS, RGS, 1495-IX, fo 27, 28; AGS, RGS, 1506-X, fo 308,309 . Posiblemente en este abuso intervencionista del prelado compostelano se encuentra el origen de la querella sobre la exención de la sede salmantina de la metrópoli compostelana, que enfrentará a ambas iglesias en tiempos de Alonso de Fonseca III y Francisco de Bobadilla.

${ }^{90}$ En este mismo año, tiene lugar una investigación real sobre los alborotos en la ciudad. Varios personajes son visitados e interrogados, entre ellos, Don Alonso, alojado en las casas que fueron de Luis de Acevedo, donde también se acoge un cierto contingente de hombres armados. (LÓPEZ BENITO, I.: Bandos nobiliarios, p. 89.). La autora de este estudio apunta también como causa principal de la division de la familia Maldonado (una parte de la cual abandona su tradicional bando de San Benito) al excesivo intervencionismo del arzobispo Fonseca en Salamanca.

${ }^{91}$ ACS, Actas Capitulares, volúmenes III y IV. 
frente compostelano, los problemas se encauzaron de modo pacífico, ya que no existe referencia en ellas a comisiones especiales del prelado o a disturbios. Ello no obsta para que las heridas permanezcan abiertas y un buen número de procesos judiciales - contra villas y caballeros- estén pendientes de resolución ${ }^{92}$.

Otra de sus preocupaciones de estos años es asegurar la posición de su nieto Alonso de Acevedo y Zúñiga, cuya madre Teresa de Zúñiga contrae un nuevo matrimonio con Fernán Pérez de Andrade. El primer paso es la fundación, en 1504, de un mayorazgo en su favor, utilizando la autorización concedida por los Reyes Católicos ${ }^{93}$. Se concertará, en 1503, una importante alianza estratégica, mediante el matrimonio de Don Alonso con doña María Pimentel, hija natural de Alonso Pimentel, Duque de Benavente ${ }^{94}$. Comienzan también las negociaciones en la corte para conseguir de Teresa de Zúñiga la entrega de los bienes y fortalezas pertenecientes al condado de Monterrey ${ }^{95}$. En 1504, tras la muerte de Lope Sánchez de Moscoso, don Alonso de Acevedo recibe de su abuelo la alta dignidad de pertiguero mayor de la Tierra de Santiago ${ }^{96}$.

Existen referencias, si bien oscuras, de un viaje de Don Alonso a la corte romana en 1506. Si las razones de este viaje no están muy claras, sí pueden apuntarse varias hipótesis: asegurar la sucesión de su hijo en la sede compostelana, el enfrentamiento con el obispo de Salamanca, el conflicto con el cardenal Cisneros sobre la primacía de la Iglesia compostelana o incluso intentar encontrar solución favorable al conflicto de

\footnotetext{
${ }^{92}$ De hecho, el destierro de su hijo Alonso de la ciudad compostelana en 1496 apunta a la existencia de tensiones de la Iglesia con la Audiencia del Reino de Galicia. En la misma línea debe interpretarse la referencia al debate sobre la jurisdicción compostelana en el testamento de la reina Doña Isabel.

${ }^{93} \mathrm{RAH}, \mathrm{Col}$. Salazar y Castro, $\mathrm{n}^{\circ} 52.855$. Poco antes de su muerte, el prelado añadirá nuevos bienes a este vínculo (Ibidem, $\mathrm{n}^{\circ} 52.856$ ).

${ }^{94} \mathrm{RAH}$, Col. Salazar y Castro, $\mathrm{n}^{\circ} \mathrm{s} 52.876,52.879,52.879$.

${ }^{95} \mathrm{Se}$ inicia aquí un largo proceso judicial por la propiedad de los bienes de la casa de Ulloa que acabará amargando las relaciones entre madre e hijo y, muy posiblemente, las de Alonso de Fonseca III y Fernán Pérez de Andrade (GARCÍA ORO, J.: Don Fernando de Andrade, conde de Villalba. Santiago, 1994; pp. 177-183).

${ }^{96} \mathrm{RAH}$, Col. Salazar y Castro, $\mathrm{n}^{\circ} 57.600$.
}

"CUADERNOS DE ESTUDIOS GALLEGOS", Tomo XLVII, Fascículo 112, Santiago 2000. 
las iglesias gallegas con los caballeros a causa de los beneficios eclesiásticos ${ }^{97}$.

En cualquier caso, la sucesión en la sede por su hijo Don Alonso necesariamente entra en los planes de esta visita, dado que la complejidad del tema indica que se trata de una operación delicada, pero profundamente madurada. Según los cronistas de la época, ya en este año de 1506 la corte trabaja en la provisión de la sede a favor de don Alonso y, muy posiblemente, éste sea uno de los motivos del viaje del joven arcediano a Italia en el séquito del rey Don Fernando ${ }^{98}$. Las gestiones realizadas por él mismo y por los agentes regios dieron resultado en el verano-otoño de 1507, cuando el cardenal Pedro Luis Borja es nombrado temporalmente arzobispo compostelano (del 28 de agosto al 23 de octubre) $)^{99}$. En diciembre de ese

${ }^{97}$ El desencuentro de Fonseca con el cardenal Cisneros sobre la primacía de sus Iglesias se enmarca dentro de una serie de disputas y procesos que inicia la iglesia compostelana con otras sedes castellanas en esta centuria; en este preciso caso, no sería aventurado suponer la existencia de un trasfondo político; véase sobre ello la misiva que el prelado compostelano dirige a Cisneros sobre el tema en RAH, Col. Salazar y Castro, $\mathrm{n}^{\circ}$ 62.167. El disfrute de beneficios y diezmos eclesiásticos por parte de laicos -ya sea con derecho o sin él- es una cuestión que enmaraña a lo largo de todo el siglo las relaciones de las iglesias gallegas con los caballeros; cuando los impulsos reformadores dentro de la iglesia castellana se acentúan a partir de la década de los 80 , el desencuentro es inevitable y los hidalgos conformarán un frente común en defensa de sus intereses. Sobre este asunto GARCÍA ORO, J.: Galicia en los siglos XIV y XV, v. I, pp. 393-394 y GARCÍA ORO, J.: Galicia na Baixa Idade Media, pp. 243-248; 338-347.

${ }^{98}$ La designación de Alonso de Fonseca y Ulloa para regir la Iglesia compostelana suscita una importante resistencia en la Corte, si bien es evidente que su éxito se debe a la existencia de influyentes razones y apoyos. Este acontecimiento es registrado en un buen número de testimonios coetáneos si bien se nos esconden las razones de fondo (BOLETÍN de la Real Academia Gallega: Colección de Documentos Históricos. 2 v., La Coruña, 1915; doc. n XXI; GALÍNDEZ, A.: Anales Breves de los Reyes Católicos. Biblioteca de Autores Españoles, Madrid, 1878; pp. 556-557; GARCÍA ORO, J.: Galicia en los siglos $X I V y X V$, v. I, pp. 466-469).

${ }^{99}$ GARCÍA ORO, J.: Galicia en los siglos XIV y XV, v. I, p. 466-469; EUBEL, C.: Hierarchia catholica medii [et recentiores] aevi sive summorum Pontificum, S.R.E. cardenalium. Monasterii, 1913-1978; v.II, p. 173; COTARELO, A.: «Un arcebispo de Santiago descoñecido» en Nos, 15-02-1926, pp. 3-4; La intervención de este personaje podría dar una nueva pista sobre un tercer elemento a tener en cuenta en toda esta cuestión: los agentes e influencias movidas por el prelado y el rey en Roma. Si bien no puede establecerse de modo claro, ciertos indicios apuntan, por un lado, a una estrecha relación del arzobispo Fonseca con la familia Borja y, por otro, es necesario recordar la presencia 
mismo año Don Alonso de Fonseca III es proveído de la sede compostela$\mathrm{na}^{100}$, mientras que su padre es promovido al patriarcado de Alejandría ${ }^{101}$. De este modo, se cubre la apariencia de la sucesión hereditaria. No obstante, toda esta maniobra esconde un último movimiento: se reserva al nuevo patriarca el derecho al disfrute de la iglesia compostelana en caso de vacante. En virtud de esta concesión pontificia, Alonso de Fonseca toma posesión de la sede -a través de procuradores y previa autorización del ahora prelado titular- el 8 de abril de $1508^{102}$.

Tras el relevo en la iglesia compostelana, parece que el nuevo patriarca asume, por delegación de su hijo, las funciones metropolitanas de la iglesia compostelana y, con ello, la presidencia del tribunal que por tradición se asienta en Salamanca ${ }^{103}$. Nuevamente los conflictos marcan el paso de Don Alonso por esta institución. Dos son las entidades con las que el Patriarca se va a enfrentar: el episcopado y la universidad salmantina. El primero, ocupado sucesivamente por Juan de Castilla y Francisco de Bobadilla, intentará por todos los medios evitar la intervención directa de Fonseca en los asuntos diocesanos y, de hecho, Bobadilla acabará consiguiendo en la corte romana un privilegio de exención de su sede y de inmediata obediencia pontificia ${ }^{104}$. El choque con el estudio salmantino

en Roma de Antonio Flores, obispo de Castellamare y Avignon, renombrado jurista y cercano a los papas Alejandro VI y Julio II. Este individuo, de origen salmantino, fue también canónigo sevillano y su familia pertenece al bando de San Benito de esta ciudad; asimismo, varias personas de este apellido aparecen en diferentes momentos al servicio del prelado compostelano.

${ }^{100}$ AHDS, Fondo General, Leg. 219-1. Según Eubel, el nombramiento tiene lugar en agosto de 1507, sin embargo, los documentos romanos incluidos en el mencionado legajo datan de diciembre de ese año.

${ }^{101}$ Ibidem.

${ }^{102}$ Ibidem.

${ }^{103}$ Durante este período el ya patriarca alejandrino mantiene su política de claro intervencionismo en la vida eclesiástica -e incluso civil- de la ciudad Salmantina (BELTRÁN DE HEREDIA, V.: Cartulario, v. III, pp. 444-446). No existe clara constancia documental de que su hijo haya delegado en él las atribuciones metropolitanas, hecho que los contemporáneos dan por cierto.

${ }^{104}$ Esta cuestión, que llegar a crear una verdadera escisión en la sociedad salmantina y constituye un problema de gran magnitud para la Iglesia compostelana que invertirá importantes recursos en él, no ha merecido hasta el momento la atención de los investigadores. Las líneas generales de su desarrollo pueden encontrarse en AHDS, Fondo General, Leg. 501, 4, fo 39r-40r y LÓPEZ BENITO, I.: Bandos, p. 92.

"CUADERNOS DE ESTUdiOS GALLEGOS", Tomo XLVII, Fascículo 112, Santiago 2000. 
tiene lugar a raíz de sus intentos por imponer sus candidatos en para la provisión de ciertas cátedras; no se trata de un enfrentamiento frontal, pero sí de una escaramuza que acabará provocando el encastillamiento de la catedral salmantina ${ }^{105}$.

A pesar de su edad, el Patriarca mantiene su actividad y energías hasta sus últimos días, tal y como se deduce de la documentación localizada. Fallece en Salamanca el 12 de marzo de 1512, siendo sepultado, aunque años después, en el monasterio de laAnunciación -o de Santa Úrsula-por él fundado en dicha ciudad.

Esta fundación introduce un aspecto de la vida de DonAlonso que aún carece de un estudio en profundidad. Es constante en la historiografía la referencia a los Fonseca -muy especialmente respecto a su hijo, pero también en relación a él y a la familia en general-como importantes patronos de las artes y las letras, en particular como impulsores del humanismo en Castilla. En líneas generales, la información disponible sobre esta faceta de su personalidad es muy escasa; pueden, no obstante, establecerse algunos hechos.

En las décadas de 1490 y 1500 existen algunas ediciones impresas que le son dedicadas ${ }^{106}$ : Antonio Geraldino, uno de los primeros humanistas italianos que llega a España, le dedica su Carmen bucolicum ${ }^{107}$; Marcos Durán, su Summula de canto de organo ${ }^{108}$; asimismo, la edición que se hace en Sevilla en 1491 de De synonymis elegantibus de Alonso de Palencia ${ }^{109}$.

${ }^{105}$ BELTRÁN DE HEREDIA, V.: loc. cit.

${ }^{106}$ Resulta difícil reconstruir con este único dato la calidad de la relación de un escritor con su mecenas, no obstante, parece evidente que de algún modo existe y que este tipo de dedicatorias tienen como finalidad habitual agradecer o ganar apoyos. A este respecto véanse las útiles apreciaciones de HOYOUX, J.: «Les moyens d'existence d'Erasme» en Bibliothèque d'Humanisme et renaissance. Travaux \& documents. Tome V, Paris, 1944. p. 7-50.

${ }^{107}$ Impreso en Salamanca hacia 1505 por Juan de Porras (cfr. NORTON, F.J.: Descriptive Catalogue of printing in Spain and Portugal. 1501-1520. Cambridge, 1978; $\mathrm{n}^{\circ}$ 472). Sobre la posibilidad -difícil- de que esta dedicatoria esté dirigida a su hijo, el futuro prelado, ver ODRIOZOLA, A.: «El gran Alonso III de Fonseca. Iniciación a su mecenazgo literario y musical» en Museo de Pontevedra, XIV (1960), pp. 25-37.

${ }^{108}$ Impresa en Salamanca hacia 1503. (NORTON, F.J.: op. cit., ${ }^{\circ} 544$ ).

${ }^{109}$ HAEBLER, C.: Bibliografia Ibérica del siglo XV. Leipzig, 1903=Madrid, 1992. v. $\mathrm{I}, \mathrm{n}^{\circ} 543$

"CUADERNOS DE ESTUDIOS GALLEGOS", Tomo XLVII, Fascículo 112, Santiago 2000. 
En el ámbito gallego, especial mención debe ser dedicada a la edición que patrocina en 1497 del breviario compostelano, encomendada al impresor salmantino Juan de Porras y que le acarreó problemas con el cabildo y la clerecía diocesana ${ }^{110}$. Según se desprende de las actas capitulares sobre ese tema, el arzobispo realiza el encargo sin consultar al cabildo, que el año anterior había encargado otra a Nicolás de Sajonia; el desencuentro surge cuando prelado y editor intentan imponer el monopolio de venta para su edición, que a juicio de los capitulares y clérigos es excesivamente cara.

A su muerte, realiza una generosa donación de un millón de maravedíes para las obras del nuevo claustro y dota, además, una fiesta en honor de San Ildefonso ${ }^{11}$. Sin embargo, su mayores aportaciones se dirigen hacia otra obra: el monasterio de la Anunciación de Salamanca, por él fundado $^{112}$. Esta fundación, que encaminará definitivamente su hijo, es autorizada por el papa Alejandro VI y se concibe como una institución vinculada muy especialmente a las mujeres de los linajes Acevedo, Fonseca, Ulloa y Maldonado, según rezan unas constituciones aprobadas por su hijo en $1515^{113}$. Por mandato expreso del prelado depende directamente de la Iglesia compostelana.

Las valoraciones que sobre él hacen sus contemporáneos oscilan, naturalmente, según la relación con el prelado. Quizás la más reseñable sea también la más subjetiva; se la debemos al ya mencionado Juan de Melgarejo, chantre de la Iglesia compostelana y perteneciente al círculo más cercano al prelado: fue uno de los mejores perlados que nunca ubo en esta dicha Sancta Iglesia... que hera muy letrado utriusque Iuris Doctor y hera muy grandisimo eclesiastico y gran limosnero y muy onesto y muy amigo de su Iglesia y muy buen tratador de sus subditos y que andobiera quinze o diez e seis años las armas bestidas y la lança a caballo defendiendo su arçobispado y su Iglesia de los henemigos que gelo tenian tomado y ga-

${ }^{110}$ ACS, Actas Capitulares III, fo 88r, 89v y 168r. ODRIOZOLA, A.: «Libros litúrgicos impresos para la diócesis compostelana (siglo XV)» en Cuadernos de Estudios Gallegos, t. XXX, nº 90-92 (1977), pp. 89-107.

"I' LÓPEZ FERREIRO, A.: Historia, v. VII, p. 314.

112 Ya en la década de los 80 realiza este prelado dádivas en favor de la casa, regentada por entonces por doña Sancha Maldonado (ACS, Libros de la Recabdança, Cuaderno $\left.2, f^{\mathrm{o}} 4 \mathrm{r}, 16 \mathrm{r}, 29 \mathrm{r}\right)$.

${ }^{113}$ AHDS, Fondo General, Leg. 401.

"CUADERnOS DE eStUdios GALLEGOS", Tomo XLVII, Fascículo 112, Santiago 2000. 
nado lo dellos muchas vezes derramando su sangre, perdiendo muchos criados y serbidores y deudos y pagando muchos caballos que pago a sus dueños que le servian y dando muchas limosnas a las mugeres y hijos de aquellos que morian en su serbiçio e que no solamente le bastaba la renta de su arçobispado... ni el patrimonio de sus padres ni de parientes ni de amigos que todo lo gastaba en defensa y conquista de lo sobredicho ${ }^{114}$.

\section{EL GOBIERNO DE LA IGLESIA COMPOSTELANA}

Una valoración general del pontificado de Alonso de Fonseca pasa, necesariamente, por la apreciación de los dos valores fundamentales que guían su acción política y administrativa: el afán con el que defiende su Iglesia y su innegable capacidad para el juego político. Es importante tener en cuenta también la magnitud de los problemas que ha de afrontar, los enemigos o partes contrarias a que se enfrenta y las armas de que dispone. Teniendo en cuenta todo ello, se relacionan a continuación los aspectos más importantes de su gestión; serán, simplemente, esbozados de modo breve, ya que todos ellos, al igual que los acontecimientos de la época y la biografía del prelado, merecen un estudio en profundidad que rebasa el objetivo de este artículo. Tres serán los aspectos que permitirán una aproximación, siquiera escueta, a la gestión del arzobispo Fonseca: la administración y las reformas llevadas a cabo, la defensa del señorío y los asuntos pastorales.

\section{La administración}

La falta de documentación impide aclarar-por el momento- de modo preciso el cuadro y los procedimientos de la administración arzobispal compostelana durante el siglo XV, muy especialmente en el período anterior a Fonseca. En todo caso, las resistencias y problemas que provoca la implantación de algunos aspectos del nuevo modelo invita a pensar que se introducen importantes innovaciones que, en ocasiones, quizás no son calculadas, sino fruto de las circunstancias.

${ }^{114}$ RODRÍGUEZ GONZÁLEZ, A.: Las fortalezas, 1065-1066v. En general, toda la declaración de este beneficiado constituye una loa a la gestión del arzobispo.

"CUADERNOS DE ESTUDIOS GALLEGOS", Tomo XLVII, Fascículo 112, Santiago 2000. 
Llama la atención, en primer lugar, el intenso fortalecimiento de la figura del provisor u oficial. Esta figura, presente en todas las diócesis, tiene como misión la presidencia de la Audiencia o tribunal diocesano y existe en Santiago al menos desde el siglo XIV. Por la responsabilidad que conlleva se confiere este cargo a una persona con conocimientos jurídicos que por ley y tradición disfrutará de amplios poderes y dado que con frecuencia -pero no siempre ni de modo obligatorio-recae en este personaje la gerencia de la diócesis en caso de ausencia del titular, suele ser persona de su confianza.

La diferencia, en este caso, estriba en su acusado protagonismo. Apenas presente en la documentación compostelana de épocas anteriores, resuena con fuerza en los textos de este período (y seguirá haciéndolo ya con título de provisor y vicario general bajo Alonso de Fonseca III y Juan Tavera), actuando como verdadero y omnipresente suplente arzobispal: ordena informaciones, dicta sentencias, promulga entredichos y excomuniones o realiza gestiones procesales en defensa de los intereses de su patrón $^{115}$.

Junto al provisor -casi un teniente de arzobispo- aparecen otros dos cargos que tienen relevancia en el gobierno de la diócesis: el alcalde mayor y el asistente. Este último aparece un tanto desdibujado y su labor parece concretarse en tareas de orden público o militar ${ }^{116}$; a pesar de que

\footnotetext{
${ }^{115}$ En efecto, y especialmente durante las ausencias del prelado es posible encontrar al provisor tratando con el gobernador y alcaldes mayores del reino de Galicia, presentando demandas contra ellos, dictando excomuniones contra los concejos por desobedecer la legislación arzobispal o sentenciando sobre asuntos de jurisdicción civil (AHDS, Fondo de San Martín Pinario, Sar 31, 8; AHDS, Fondo General, Leg. 70, passim; AHDS, Fondo General, Leg. 93, 5; AHDS, Fondo General, Leg. 1229, 1, fo 40r-42v, 46r-52v; ACS, Libro de Constituciones 2, fo 89v-91r; ACS, Leg. 436, sin foliar; etc.). Sobre sus atribuciones al comienzo del mandato ver VÁZQUEZ BERTOMEU, M.. Actas Capitulares, $v$. $I, \mathrm{f}^{\mathrm{o}} 19 \mathrm{r}$; en este documento se cancelan los poderes hasta entonces cedidos al provisor, que parecen concretarse básicamente al fuero eclesiástico (colación beneficial y jurisdicción espiritual).

${ }^{116}$ GARCÍA ORO, J.: Galicia en los siglos XIVy XV; v. I, p. 58; LÓPEZ FERREIRO, A.: Fueros municipales de Santiago y su Tierra. Reimp. Madrid, 1975; pp. 572-573. Este cargo apenas aparece en la documentación (AHDS, Fondo General, Leg. 219-1, f ${ }^{\mathfrak{o}} 1 \mathrm{r}-$ $2 r$ ). Dado que es una figura también existente en la ciudad de Sevilla quizás pueda encontrarse ahí su origen; tampoco la cronología de su implantación está clara, ya que puede remontarse al mandato de Don Lope de Mendoza.
}

"CUADERNOS DE ESTUDIOS GALLEGOS", Tomo XLVII, Fascículo 112, Santiago 2000. 
en el siglo siguiente ambas funciones están fusionadas en una única magistratura, parece arriesgado retrotraer esta circunstancia al período estudiado, ya que ambos cargos no aparecen en la documentación asociados a una misma persona hasta el mandato de Alonso de Fonseca III ${ }^{117}$.

$\mathrm{El}$ alcalde mayor nace, posiblemente, como consecuencia de la cada vez menor relevancia real del cargo de pertiguero mayor de la Tierra de Santiago. Ocupada esta dignidad por un caballero del enemigo linaje de los Moscoso es necesario elaborar un nuevo organigrama con un nuevo oficial -de total confianza y amplios conocimientos jurídicos-para coronar el engranaje de la jurisdicción civil ${ }^{118}$. Dentro de la política centralizadora del prelado y, teniendo en cuenta sus conflictos con los regimientos urbanos, esta magistratura nace con un cierto afán expansionista y busca una simplificación del escalafón administrativo, supone también despojar a los alcaldes ordinarios de la posibilidad de ver causas en apelación ${ }^{119}$.

El tercer gran puntal de la administración compostelana será el recaudador. Las únicas noticias precisas sobre este cargo, con anterioridad a Fonseca, remiten al mandato de don Lope de Mendoza y a su contador, secretario y recaudador Ruy Martínez de Carballido ${ }^{120}$. En tiempos de Fonseca, las amplias competencias de Carballido están divididas, correspondiendo la recaudación y gestión de las rentas arzobispales en Galicia -previa delegación expresa- al recaudador mayor ${ }^{121}$. La docu-

${ }^{117}$ Sobre la estructura administrativa en la Edad Moderna ver LÓPEZ GUTIÉRREZ, M.: Señorío y municipalidad. Santiago de Compostela, 1997; pp. 213 y ss.

${ }^{118}$ Sobre las atribuciones del pertiguero ver VILLA-AMIL Y CASTRO, J.: Los pertigueros de la Iglesia de Santiago. Madrid, 1893; GONZÁLEZ VÁZQUEZ, M.: El arzobispo de Santiago: una instancia de poder en la Edad Media (1150-1400). Santiago, 1996; pp. 211 y ss.

${ }^{119}$ Esta es la causa inmediata del conflicto con los concejos de Compostela y Noia sobre el nombramiento de alcaldes y, muy posiblemente, también de algunos choques jurisdiccionales con la Real Audiencia, a la que acudirían los descontentos de la decisión arzobispal.

${ }^{120}$ A este personaje debemos la composición del cuaderno más moderno del llamado «Tumbo Vermello» (RODRÍGUEZ GONZÁLEZ,A.: O tumbo vermello de don Lope de Mendoza. Santiago de Compostela, 1995. Anexo XXIII de Cuadernos de Estudios Gallegos).

${ }^{121}$ A tenor de la información disponible, la Cámara arzobispal está al cargo de un camarero, correspondiendo la recaudación de las rentas a dos recaudadores generales, uno para los ingresos gallegos y otro para los castellanos. Se desconoce la capacidad de

"CUADERNOS DE ESTUDIOS GALLEGOS", Tomo XLVII, Fascículo 112, Santiago 2000. 
mentación existente sobre este cargo inclina a pensar que a partir de 1483 -fecha en la que el prelado pasa a residir en Castilla- este oficial gana en atribuciones, a la vez que se convierte en un puesto de confianza; en efecto, los informes contables del tesorero Nicolás de Acevedo, designado en esta época, refieren no sólo una mayor libertad de acciónsiempre con límites- sino también una progresiva complejidad del proceso recaudatorio, especialmente en lo referente al control de los agentes locales $^{122}$.

Dado el cariz de los acontecimientos y problemas durante los años de mandato de Don Alonso estos tres oficiales son los principales de su administración y sobre ellos recaerá la gestión completa del señorío, cuando desde los años 80 el prelado se ausente de modo casi permanente, formando un sólido núcleo de gobierno.

Se advierten, además, otros síntomas de cambio. Por un lado, hay claros indicios de la existencia de juicios de residencia a ciertos oficiales de la administración, sin que pueda establecerse la posible novedad de este procedimiento; sí parece, en cambio, que en algunos ámbitos constituye una innovación que provoca fricciones. Dos casos se documentan claramente: la residencia aplicada hacia 1479 a Fernán Pérez Parragués por su gestión al frente del alfoz de Muros y coto de Xallas ${ }^{123}$; Fonseca intentó también ejercer esta prerrogativa de control sobre los alcaldes compostelanos ${ }^{124}$. Por otro, la documentación económica de la mesa arzobispal -la más abundante conservada referente a este mandato- deja traslucir, a falta de un estudio en profundidad, un organigrama administrativo bastante sólido y estructurado que se concreta en la existencia de mecanismos de

gestión e iniciativa del recaudador castellano. Las rentas y el aparato administrativo de la diócesis compostelana parecen tener un cierto margen de independencia en las cuestiones económicas (ACS, Libros de la Recabdança).

${ }^{122}$ ACS, Libros de la Recabdança, Cuaderno 2.

${ }^{123}$ APONTE, V.: Recuento, párr. 260. El pasaje de referencia presenta ciertas dificultades en lo referente a la identificación del afectado, que en principio sería el mencionado (ver notas de los editores). Según este relato, a causa de este asunto el hidalgo abandona el bando arzobispal.

${ }^{124}$ Resulta significativo a este respecto que el prelado intentase aplicar la residencia a los alcaldes concejiles de la ciudad de Santiago. Esta alteración de la costumbre provoca un nuevo proceso judicial, fallado finalmente en 1521 en favor del arzobispo (AHDS, Fondo General, Leg. 93-15). 
actuación y de control de los agentes locales ${ }^{125}$; no puede afirmarse que ello sea obra del gobierno de Fonseca, si bien es una tendencia general de las haciendas y estados señoriales de la época.

El largo mandato del prelado le permite, asimismo, remodelar otros focos de poder como son alcaidías de fortalezas, regimientos o diversos oficios administrativos. Puede adivinarse, por el momento y a falta de estudios en profundidad, una filtración de personajes afectos al arzobispo a través de nombramientos en los que posiblemente se alternan las designaciones por renuncia dentro de las familias y facciones tradicionales con entradas de personas de nuevo cuño, generalmente cercanas al prelado ${ }^{126}$. Esta política no soluciona, es evidente, los roces y tensiones existentes en el señorío, pero quizás sí contribuye a encauzarlos de otro modo.

Esta solución se mantiene muy especialmente en los más altos niveles de la administración arzobispal a la que acceden mayoritariamente individuos vinculados familiarmente al prelado. En efecto, y aunque es algo tradicional en todas las iglesias, es impresionante el número de agentes arzobispales que pertenecen a las familias Maldonado, Fonseca, Acevedo, Paz, Flores,... Aparecen en todos las vertientes del gobierno pero, a diferencia de los oficiales estables, actúan siempre bajo órdenes precisas -y mandato procuratorio- del prelado, defendiendo sus intereses ante los más diversos foros y entidades ${ }^{127}$.

\section{La defensa del señorío}

El señorío temporal de los prelados compostelanos es un ente de gran complejidad y diversidad geográfica, política y económica. Es, como muchos otros, un conjunto de propiedades y rentas, jurisdicciones, derechos políticos y señoriales que se aplican de modo desigual sobre el espa-

${ }^{125}$ La situación es muy diferente a la planteada por M. González Vázquez para los siglos anteriores y que presenta una cierta situación de degradación en los últimos decenios del siglo XIV.

${ }^{126}$ Todo a lo largo de la geografía diocesana y señorial aparecen ya desde los años 70 personajes vinculados con el prelado, fácilmente identificables por sus apellidos: Paz, Ribas, Acevedo, Fonseca,... También se detecta la participación de personas relacionadas con los concejos urbanos en la administración arzobispal: los Ben de Muros, Castellano, Muros, Prego,...

${ }^{127}$ Un simple vistazo a la documentación de la época permite elaborar una relación sumaria de ellos, siendo el grupo más importante el de los canónigos.

"CUADERnOS DE ESTUdios GALLEGOS", Tomo XLVII, Fascículo 112, Santiago 2000. 
cio de la diócesis compostelana, prolongándose en ocasiones más allá de ella $^{128}$. Esta heterogeneidad es, a la vez, motivo de fortaleza y de debilidad, ya que si bien los impactos de carácter negativo suelen amortigüarse por su carácter local o sectorial, no es menos cierto que al convivir realidades muy diferenciadas dentro de un mismo territorio - que no es continuo-se generan fácilmente tensiones, ya sean por causas internas o externas. Durante el mandato de Alonso de Fonseca este señorío vive un momento de intensa transformación por la cristalización y maduración de algunos procesos de largo alcance, el nacimiento de otros y la presencia puntual de elementos coyunturales exógenos.

Tres son los principales, que no únicos, agentes que condicionan el devenir del señorío temporal de los arzobispos compostelanos en este período: los concejos -rurales y urbanos-, los caballeros -especialmente aquellos asentados en la Tierra de Santiago o sus cercanías-y la Corona en su intento de retomar su posición en Galicia-. Cada uno de estos frentes presenta una problemática propia a la que la administración arzobispal responde desde la estrategia global de defensa a ultranza de su derecho.

La relación de los prelados compostelanos con los concejos -especialmente los urbanos- es, sin duda, la cuestión más antigua y posiblemente aquélla en la que las partes ensayaron mayor número de soluciones ${ }^{129}$. Resulta evidente que en este momento existe en los concejos rurales y urbanos del señorío compostelano cierta madurez política y organizativa, cuyos hitos más visibles en estos años son la liga o confederación constituida por las más importantes ciudades del señorío con los caballeros que

${ }^{128}$ Sobre las características de este señorío, en profundidad, ver GONZÁLEZ VÁZQUEZ, M.: op. cit.

${ }^{129}$ La obra de A. López Ferreiro Fueros municipales de Santiago y su tierra sigue siendo fundamental para el estudio de este tema, no sólo por la ingente cantidad de documentación que aporta, sino también por algunas de sus apreciaciones sobre los hechos. No obstante, es necesario recalcar su insuficiencia en muchos aspectos, circunstancia que no parece haber movido a la actual historiografía a revisar la cuestión de modo global; sí existen, en cambio, nuevas investigaciones de carácter local: ARMAS CASTRO, J.: Pontevedra en los siglos XII a XV. Coruña, 1992; LÓPEZ DÍAZ, M.: op. cit.; REI, X.; FRAMIÑÁN SANTAS, A.: «Os tempos medios» en CORES TRASMONTE, B.: Historia de Cee. Cee, 1999; pp. 171-235.

"CUADERNOS DE ESTUDIOS GALLEGOS", Tomo XLVII, Fascículo 112, Santiago 2000. 
se enfrentan al arzobispo en $1458^{130}$, la rápida expansión de la Hermandad de 1467 y su capacidad organizativa y ejecutiva y, finalmente, el cúmulo de quejas, resistencias y procesos judiciales que desde los años 80 se documentan contra el prelado y sus agentes. Respecto a esta última cuestión es importante señalar que la protagonizan no sólo las ciudades, sino también concejos y comunidades rurales.

Desde su llegada a Santiago, y mucho más desde su efectiva toma de posesión del señorío en 1469 , la política seguida por el prelado en este tema es la de los hechos consumados y busca claramente fortalecer su posición. Dos son los principales conflictos que enfrentan al arzobispo con sus concejos: la fiscalidad y el nombramiento de alcaldes en Santiago y Noia. El primero de ellos, presente seguramente de modo puntual y local desde muy antiguo, adquiere gran magnitud en los años 80 y 90 . Buscando reparar las maltrechas finanzas de la mesa arzobispal, se reorganiza la administración y se crean mecanismos claros para la ejecución de las deudas y vencer las resistencias al pago; muy posiblemente se intenta también cobrar rentas en desuso y beneficiar rentas reales como la alcabala ${ }^{131}$. El uso de métodos coercitivos -temporales y espirituales-por parte de los administradores arzobispales contribuye al recrudecimiento de las tensiones. En algunos momentos puede hablarse claramente de abierta rebelión fiscal que se ampara en la supuesta arbitrariedad señorial. Un factor que seguramente incide en el comportamiento de ambas partes respecto a este asunto es la congelación por parte real del privilegio de las alcabalas que

${ }^{130}$ Editado el documento en PALLARES, M.C.; PORTELA, E.: Galicia na época medieval A Coruña, 1991; pp. 477-480. En él se testimonia claramente una nueva estrategia de los concejos en su objetivo de liberarse del señorío arzobispal: la alianza de partes con un enemigo común. Su resultado - de cara a las pretensiones ciudadanas- no es positivo, no sólo porque finalmente los prelados recuperasen el poder en las villas sino porque, según todos los indicios la ausencia de don Rodrigo de Luna no supuso necesariamente su «libertad». Este experimento pudo condicionar en algún modo las relaciones de los concejos, especialmente el compostelano, con la nobleza gallega muy en particular con aquella que es ajena a su entorno.

${ }^{131}$ ACS, Libros de la recabdança, passim. Concretamente, el cobro de la alcabala que comienza como una disputa entre la corona y el arzobispo y tiene un marcado caracter local- acaba implicando a diversos concejos rurales y urbanos a lo largo de toda la geografía diocesana (REI, X; FRAMIÑÁN SANTAS, A.: op. cit., pp. 224-227; FERNÁNDEZ CORTIZO, C.: «Las alcabalas enajenadas en la provincia de Santiago: los 'reguengos' de la Mitra compostelana (ss. XV-XIX)» en Obradoiro de Historia Moderna 2, (1993), pp. 127-142).

"CUADERNOS DE ESTUDIOS GALLEGOS", Tomo XLVII, Fascículo 112, Santiago 2000. 
en ciertas zonas (los «reguengos») cobra el arzobispo; sobre ello se llega a un pacto que supone para el arzobispo seguir recibiéndolas temporalmente -contribuyendo así a la recuperación de la menguada mesa de la mitra-y, quizás, le alienta a movimientos de carácter similar ${ }^{132}$. Desde el punto de vista concejil, el embargo regio siembra la duda sobre la legalidad de las percepciones arzobispales, así que se sucederán durante estos años multitud de procesos judiciales en Santiago y en Valladolid sobre este tema -y que serán heredados por otros prelados-. Serán acompañados de las correspondientes cartas reales a las partes solicitando su moderación. Parece, no obstante, que la decisión regia de encaminar la disputa por el cauce procesal, concediendo mientras al prelado el disfrute de esta renta, encamina las energías de ambas partes de modo que la situación no se deteriore en demasía.

Las villas de Santiago y Noia se enfrentaron directamente al prelado por su capacidad para nombrar alcaldes ${ }^{133}$. La tradición impone que en las villas del señorío arzobispal, cada concejo elabora anualmente una relación de candidatos (cobres o cobrados) -de número variable según el tamaño de la población y con un máximo de 12 para el caso de Santiagoque es presentada al arzobispo. De entre los candidatos presentados, el prelado elige a aquellos que durante el año ejercerán el oficio de alcaldía (alcaldes o justiçias). En principio, las atribuciones de estos oficiales concejiles atañen a la jurisdicción local criminal y a la civil en primera -aunque no obligatoria-instancia ${ }^{134}$; aunque la documentación no es cla-

${ }^{132}$ No hay que perder de vista la influencia que las élites comerciales profesionales y de la pequeña hidalguía -asentadas plenamente en los concejos- pueden tener en el desarrollo de este conflicto. Muy posiblemente ellas serían las beneficiarias de los contratos de arrendamiento para la recaudación local de esta renta -con las ganancias que ello conlleva-; la titularidad arzobispal plena de la alcabala supone -a tenor de las informaciones disponibles- la utilización del sistema de recaudación a través de fieles.

${ }^{133}$ Parece que este conflicto no se presenta en otros lugares de la Tierra de Santiago. Quizás ello se debe a la distinta configuración de las élites concejiles -entre las que se eligen los alcaldes- o, en el caso de Pontevedra a las difíciles circunstancias durante algún tiempo -varios años amenazada y ocupada por Pedro Álvarez de Sotomayor-o en Muros, a la constante presión del señor de Altamira.

${ }^{134}$ Sobre estos oficiales, LOPEZ DÍAZ, M.: Señorio, pp. 214-220. Aunque este estudio se centra especialmente en el desarrollo de esta oficialidad durante la Edad Moderna, las apreciaciones son de gran valor y pueden tomarse con las debidas precaucionescomo punto de partida para el acercamiento a esta cuestión en el período medieval. 
ra a este respecto, parece que la apelación de sus sentencias se realiza, en los casos criminales, al tribunal del Pertiguero Mayor de la Tierra de Santiago y, en los civiles, al arzobispo o sus audiencias delegadas (provisor); en cualquier caso, se remiten a los tribunales señoriales. A estas alturas está claro que el arzobispo Fonseca intenta una reforma en profundidad de la administración judicial de su señorío, aunque no puedan estimarse claramente las fases de su desarrollo, ni tan siquiera el organigrama final (que no se manifiesta con nitidez años después) ${ }^{135}$. La centralización de la administración señorial planteada por el arzobispo Fonseca supone también la de la judicial y así, la creación del cargo de asistente y el alcalde mayor, así como el progresivo crecimiento de las atribuciones del provisor son pruebas evidentes de esta reorganización, mientras que el conflicto con el Bernal Yáñez de Moscoso, escondería la lateralización del Pertiguero Mayor, máxima autoridad judicial seglar, en beneficio de un oficio de plena dependencia respecto al prelado ${ }^{136}$. En efecto, el reforzamiento de la autoridad arzobispal pasa por controlar también el organigrama judicial y, además de soslayar la autoridad del pertiguero, por reformar la justicia concejil. Según los indicios, el cambio se intenta por el camino de la designación de los jueces eliminando la participacion de las comunidades por la vía de los cobres.

Durante varios años, el arzobispo Fonseca se niega a recibir el documento de designación que le envían los concejos de Santiago y Noia, bloqueando la actuación de los alcaldes ordinarios. Cabe pensar también que en este asunto esconden ambas partes motivaciones de mayor alcance: los

\footnotetext{
${ }^{135}$ Ya en su forma final HOYO, Jerónimo del: Memorias del arzobispado de Santiago (1607). Edición por A. Rodríguez González y B. Varela Jácome. Santiago de Compostela, s.d.; pp. 6-9; LÓPEZ DÍAZ, M.: Señorio, pp. 213 y ss.

${ }^{136}$ Ya en el siglo XV el cargo de Pertiguero Mayor de Santiago tiene un carácter fuertemente honorífico y es concedido por los prelados a aquellos caballeros más importantes del señorío o a sus parientes de mayor confianza. No obstante, el tribunal sigue existiendo, al igual que una extensa red de pertigueros menores -de carácter local- posiblemente dependientes de algún modo de su autoridad. Como es habitual en la época, la presidencia de estos tribunales conlleva rentas y atribuciones que en este caso son difíciles de precisar, pero hacen de esta dignidad algo deseable por muchos caballeros. Si bien no es creíble ver en este asunto el motivo único de la larga disputa que enfrenta al arzobispo con Bernal Yáñez -y luego a sus sucesores-, tal y como apunta Vasco da Ponte, también es verdad que, sin duda, es uno de los factores que encendieron el fuego de la discordia.
}

"CUADERNOS DE ESTUDIOS GALLEGOS", Tomo XLVII, Fascículo 112, Santiago 2000. 
concejos, enfrentados ya al prelado por asuntos fiscales, recurren al gobernador real -quizás buscando que la Corona reclame para sí las apelaciones de los tribunales locales-; Fonseca, que tiene en cuenta el creciente fortalecimiento de la autoridad real y ve peligrar su autoridad -de hecho, a través de las resistencias locales, y de derecho, en caso de una intervención directa de los delegados reales-, pretendería posicionar personas fiables al frente de estas entidades para sofocar cualquier movimiento contrario.

Este conflicto, que parece existir al menos desde 1487, tiene una primera solución en 1493, cuando una real ejecutoria compele a las partes a volver a la tradición: el arzobispo debe recibir las cartas de los cobres y de entre ellos designar a los alcaldes; los concejos deben remitir sus apelaciones al tribunal señorial. Este conflicto, especialmente por lo que respecta al concejo compostelano, empañará las relaciones con el arzobispo durante muchas décadas ${ }^{137}$.

La mayor dificultad con la que se enfrenta el arzobispo Fonseca, al igual que sus predecesores, es su difícil relación con los caballeros asentados en su archidiócesis o en las cercanías de ella. Esta cuestión es la que necesita una mayor inversión de energía y, sobre todo, de dinero. Básicamente es una lucha por la supervivencia: por un lado, los caballeros que pertenecen a linajes ascendidos por el rey Enrique II necesitan, para su subsistencia económica y social, del disfrute -a modo de intermediariosde tierras, jurisdicciones y rentas que pertenecen a las instituciones eclesiásticas, que en realidad son las grandes propietarias de bienes y rentas en Galicia. Ello se debe a la dificultades que tienen para cubrir sus necesidades económicas, políticas y sociales con unos estados que, territorial y económicamente, son insuficientes. La posesión-que no propiedad-de jurisdicciones reales pero sobre todo eclesiásticas o la administración de cotos donde se entremezclan jurisdicción, propiedad, derechos de patronazgo, el beneficio de rentas reales,... constituirán las bases fundamenta-

${ }^{137}$ Toda la documentación relativa a este asunto se encuentra en AHDS, FG, Leg. 93. El proceso que enfrentó durante años al prelado y al concejo compostelano ha sido estudiado por LÓPEZ DÍAZ, M.: Señorío, passim, muy especialmente la primera parte de la obra. En general, sobre el tema, GARCÍA ORO, J.: Galicia en los siglos XIV y XV. v. II, pp. $60-62,178-179$.

"CUADERNOS DE ESTUDIOS GALLEGOS", Tomo XLVII, Fascículo 112, Santiago 2000. 
les de subsistencia a todos los niveles. Inevitablemente, las concesiones limitadas y temporales que en su favor realizan prelados, monasterios y cabildos acaban siendo percibidas por los caballeros como derecho propio y las crisis agrícolas del siglo XV les moverán a luchar entre ellos para ampliar sus ingresos. Si a ello se unen las convulsiones políticas del siglo XV castellano, no será dificil comprender algunos de los acontecimientos y procesos protagonizados por este grupo social.

En torno al arzobispado de Santiago se mueven los linajes de los Moscoso y Sotomayor, en su rama principal y la de Lantaño, alrededor de los cuales existen otras casas de menor entidad tales como los Xunqueiras, Montenegro, Montaos,... Tienen también intereses en este territorio ya sea de modo directo o indirecto -a través de alianzas, por ejemplo-, casi todos los grandes señores de Galicia ${ }^{138}$. Dado que las líneas generales de la conflictividad son sobradamente conocidas, únicamente se hace necesario recalcar que se trata de acontecimientos de gran complejidad en los que no parecen existir explicaciones simples ni únicas.

En la relación del arzobispo Fonseca con los caballeros pueden distinguirse dos fases claramente diferenciadas y cronólogicamente sucesivas. La primera de ellas, que se desarrolla hasta el primer «exilio» del prelado en la corte se caracteriza por la actividad militar. Tal y como recuerda su "criado" Juan de Melgarejo, el arzobispo andobiera quinze o diez e seis años las armas bestidas y la lança a caballo; en efecto, son años de guerra constante, primero para asentar su autoridad, luego contra Bernal Yáñez de Moscoso, su pertiguero y por ello caballero más importante, más tarde contra los Irmandiños y, finalmente, contra los caballeros que disfrutan sin justos títulos los bienes eclesiásticos. Son tiempos de armas y de alianzas cambiantes, en función de intereses puntuales o de los acontecimientos generales del reino, pero también de apuros económicos, ya que la coyuntura general, los abundantes gastos y la ocupación de bienes y rentas impiden la reconstrucción de la mesa arzobispal ${ }^{139}$.

${ }^{138}$ GARCÍA ORO, J.: La nobleza gallega en la Baja Edad Media. Santiago de Compostela, 1981.

${ }^{139}$ Los testigos del pleito Tabera-Fonseca hacen referencia frecuentemente a las dificultades monetarias del prelado que impidieron reconstrucción efectiva y a tiempo de las fortalezas; refieren también las escaramuzas y construcciones defensivas costeadas por el prelado. La contabilidad de los años 80 menciona también no sólo gastos por estos 
Su participación decisiva en los sucesos gallegos del conflicto sucesorio castellano apuntalan la posición del arzobispo Fonseca en la Corte, hecho que le será de gran ayuda en los años que vive fuera de su sede. Terminados los años de guerra, las diferencias del prelado con los caballeros se dirimen generalmente en el terreno judicial -con rebrotes violentos esporádicos-; en casi todos los casos la Corona -motu propio o por presión-resguarda la posición fonsecana ${ }^{140}$. Los principales procesos dirimidos por la mitra compostelana son:

- Contra los caballeros de la Tierra de Santiago sobre la jurisdicción: se inicia en un momento impreciso (posiblemente en los años de 1490) y en 1503 entra en apelación en el Consejo Real ${ }^{141}$.

- Contra el Conde de Altamira por la ocupación de jurisdicción eclesiástica en ciertas feligresías del Camino Francés ${ }^{142}$.

- Contra el mismo Conde: sobre la jurisdicción de Mesía, Malpica y Cira con su merindad ${ }^{143}$.

- Contra el Duque de Alburquerque y la villa de Ledesma sobre la jurisdicción de la villa de Palacios ${ }^{144}$.

conceptos, sino también embargos y resistencias a la fiscalidad arzobispal. Quizás por su cercanía y trato personal con Fonseca resulta de gran interés -aunque hay que recordar su parcialidad- la declaración del chantre Juan de Melgarejo en el mencionado proceso ( $v d$. supra). Vasco da Ponte y, tomándolo como referencia, la historiografía contemporánea han estudiado estos acontecimientos, si bien es muy necesaria una revisión de conjunto a la luz de nuevas investigaciones, asi como un acercamiento pormenorizado a los linajes relacionados con esta cuestión.

${ }^{140}$ Un repaso a la documentación real y acontecimientos de este período permite observar cómo si bien es habitual una amonestación regia a los agentes arzobispales o al prelado mismo por sus excesos, no es menos cierto que generalmente los reyes acaban apoyando sus pretensiones o salvaguardando sus intereses. Brevemente mencionados pueden encontrarse en AHDS, Fondo General, Leg. 501, 4.

${ }^{141}$ El escrito de apelación presentado por la parte arzobispal se encuentra en AHDS, Fondo General, Leg. 93-2-6 y Leg. 93, 6.

${ }^{142}$ Apelado en 1501 (AHDS, Fondo General, Leg. 6, fo 12r-28v; Leg. 93-7).

${ }^{143}$ VÁZQUEZ BERTOMEU, M.: «El libro memorial de los pleitos del arzobispo Fonseca III (1524)» en Compostellanum (en prensa); AHDS, Fondo General, Leg. 90-3, $\mathrm{f}^{\mathrm{o}} 48 \mathrm{v}$. La primera sentencia del proceso de Mesía data de 1509.

${ }^{144}$ AHDS, Fondo General, Leg. 93-7; Leg. 6. La villa de Palacios, perteneciente a la diócesis de Zamora, forma parte de la vicaría de Alba y Aliste, donde el arzobispo compostelano posee derechos jurisdiccionales eclesiásticos y seglares. 
- Con Suero Gómez de Sotomayor sobre más de una decena de feligresías del arcedianato de Salnés y del arciprestazgo de Postmar$\cos ^{145}$

- Con Fernán Pérez de Andrade sobre el beneficio de Tiobre ${ }^{146}$.

- Contra Enrique Enríquez de Guzmán que tiene usurpada la jurisdicción de Vea ${ }^{147}$.

- Con el Conde de Altamira sobre la villa de Fisterra ${ }^{148}$.

Buena parte de estos procesos se alargaron durante muchos años tal y como se desprende de la documentación correspondiente al mandato de su hijo ${ }^{149}$, si bien parece que no dan lugar a crisis de carácter violento.

\section{El gobierno de la diócesis}

Aunque el mandato del arzobispo Fonseca está sembrado de problemas, hay indicios claros que permiten afirmar que, en ningún modo, la Iglesia Compostelana permanece en el desgobierno. El mando corresponde al prelado al que, por lo menos en los años 70 y primeros 80 , encontramos ejerciendo labores inherentes a su dignidad en reuniones capitulares, confiriendo beneficios y órdenes eclesiásticas, nombrando canónigos, .... No obstante, es lícito pensar que su intervención directa en los asuntos más cotidianos es escasa durante estos años y casi nula en las décadas siguientes, encargando a sus colaboradores más directos el día a día. Éstos son principalmente el provisor y un obispo auxiliar cuyas funciones tienden a suplir las diversas facetas de la realidad episcopal: jurisdicción, pastoral y materias beneficiales.

El provisor es el juez delegado ordinario, presidente del tribunal eclesiástico arzobispal por delegación del prelado; ello supone que juzga las

${ }^{145}$ VÁZQUEZ BERTOMEU, M.: op. cit.

${ }^{146}$ AHDS, Fondo General, Leg. 1229, $\mathrm{f}^{\mathrm{o}} 33 \mathrm{r}$ ins. (1493).

${ }^{147}$ AHDS, Fondo General, Leg. 1229, fo 40r-42v (1496). Don Enrique es nieto de Suero Gómez de Sotomayor contra el que muy posiblemente se inició el proceso.

${ }^{148}$ ACS, Libros de la Recabdança, Cuaderno 2, $\mathrm{f}^{\circ} 5 \mathrm{r}$.

${ }^{149} \mathrm{La}$ relación de procesos judiciales pendientes en 1524 cuando Alonso de Fonseca III es trasladado a Toledo puede encontrarse en VÁZQUEZ BERTOMEU, M.: El memorial.

"CUADERNOS DE ESTUDIOS GALLEGOS", Tomo XLVII, Fascículo 112, Santiago 2000. 
causas de su audiencia, confiere beneficios, provee oficios ${ }^{150}, \ldots$ Ejercerán tal cargo Juan García de Gómara ${ }^{151}$, Juan de Montemayor ${ }^{152}$, Rodrigo de Acevedo $^{153}$, Fr. Gonzalo de Ribera ${ }^{154}$-abad de Poio-y Pedro de Soto ${ }^{155}$; siendo el primero y el último de los mencionados aquellos que actúan de modo más continuado. A tenor de los textos, el provisor es también vicario general de la diócesis, lo que le hace aparecer como verdadero hombre fuerte, que dispone de cierta autonomía-siempre dentro de los poderes conferidos por el prelado-, al menos en los negocios espirituales.

$\mathrm{Al}$ obispo auxiliar, en cambio, corresponden aquellas atribuciones reservadas al obispo ordenado: conferir órdenes, absolución de casos reservados, celebraciones en pontificales ${ }^{156}, \ldots$ así como los asuntos de carácter estrictamente pastoral, tales como la visita diocesana o la imposición de órdenes sacerdotales. En estos años varios obispos, de los conocidos como in partibus infidelium - esto es, ordenados pero sin obligación de residencia en su iglesia- permanecen en Compostela y ejercen funciones episcopales. Son Vasco de Bite ${ }^{157}$-obispo de Sebas-

${ }^{150}$ Pormenorizadamente se desglosan las atribuciones que tiene en la iglesia compostelana en un documento de revocación otorgado por el arzobispo Fonseca en 1467 (VÁZQUEZ BERTOMEU, M.: Actas Capitulares, v. I, fo 19r).

${ }^{151}$ Es su primer provisor, tomando posesión con la llegada de Fonseca a Santiago (VÁZQUEZ BERTOMEU, M.: Actas Capitulares, v. $I, \mathrm{f}^{\mathrm{0}} 3 \mathrm{r}$ ) hasta su fallecimiento hacia 1486 (JUSTO MARTÍN, M.X.; LUCAS ÁLVAREZ, M.: Fontes documentais da Universidade de Santiago de Compostela. Santiago, 1991; doc. ${ }^{\circ}$ 353; ACS, Libros de la Recabdança, Cuaderno 2, $\mathrm{f}^{\mathrm{D}} 5 \mathrm{r}$ ).

${ }^{152}$ Ejerce durante un período corto de 1485, quizás por ausencia o enfermedad del titular (AHDS, Fondo de San Martín Pinario, Sar, Leg. 14, 7).

${ }^{153} 1493$ (AHDS, Fondo General, Leg. 93-1).

${ }^{154}$ Desde 1486 (JUSTO MARTIN, M.X.; LUCAS ÁlVAREZ, M.: op. cit., doc. $\mathrm{n}^{\circ}$ 354) hasta su muerte, que debió tener pocos años después (ACS, Libros de la Recabdança, Cuaderno 2, $\mathrm{f}^{\mathrm{o}} 7 \mathrm{r}$ ).

${ }^{155}$ Parece ejercer entre 1496 (AHDS, Fondo General, Leg. 1229, fo 40r-42v) y 1508 (AHDS, Fondo General, Leg. 219-1). Brevemente, su biografía ha sido trazada por LÓPEZ FERREIRO, A.: Galicia, p. 196.

${ }^{156}$ Como ya se ha dicho, en 1467 el arzobispo revoca los poderes dados a su obispo auxiliar y al provisor (ver supra). Parece, no obstante, que este prelado actúa por delegación no sólo del arzobispo, sino también de su provisor.

${ }^{157}$ Maestro en teología, pertenece a la Orden de los Predicadores; nombrado en 1442 es facultado para ejercer en la ciudad y diócesis compostelana (EUBEL, K.: Hierarchia catholica, v. II, p. 232; VÁZQUEZ BERTOMEU, M.: Actas capitulares. v. I, fo 19r; LÓPEZ FERREIRO, A.: Galicia, p. 142). 
tia-, Suero de $\mathrm{Oca}^{158}$-arzobispo de Tarso-, Alonso de Castilla -de Berito- ${ }^{159}$.

Tenemos constancia de la celebración en estos años de, al menos, un sínodo $(1508)^{160}$ y existe un interesante corpus de documentos relativos a visitas a iglesias que, entre otras noticias, informa de la existencia de un visitador diocesano ${ }^{161}$. Hay también referencias claras a la visitación de los hospitales compostelanos por orden del prelado ${ }^{162}$. Precisamente, el derecho arzobispal a visitar los templos y clerecía de su distrito da lugar a un complejo conflicto con el monasterio de San Martín Pinario, que se resiste y apela contra esta intervención ${ }^{163}$.

El otro gran problema de la administración eclesiástica será la ocupación de bienes y beneficios de la Iglesia por parte de los caballeros gallegos. En este aspecto, la política fonsecana sigue las mismas directrices que aquella de carácter seglar: defensa a ultranza del derecho jacobeo.

No obstante, el frente más doloroso es, sin duda, el que reside en su propia Iglesia. En efecto, los documentos de la corporación capitular reflejan con claridad meridiana la existencia de una relación difícil, que

${ }^{158}$ Sobre este personaje ver GARCÍA ORO, J.: «D. Suero de Oca (X-1513). El caballero. El abad. El arzobispo» en Cuadernos de Estudios Gallegos t. XXIII, nº 69 (1968), pp. 45-69; EUBEL, K.: Hierarchia catholica, v. II, p. 232.

${ }^{159}$ Pertenece a la orden franciscana, nombrado en 1497 (EUBEL, K.: Hierarchia catholica, v. II, p.105; LÓPEZ FERREIRO, A.: Galicia, p. 196). Eubel menciona en su relación de obispos auxiliares de la diócesis compostelana (Ibidem, p. 274) la existencia de un Diego, maestrescuela compostelano, designado obispo de Berito en 1493, que fallece en 1496, siendo sucedido por Alonso de Castilla (Ibidem, p. 105). El maestrescuela compostelano de este período es Diego de Castilla -hermano de Alonso-, fallecido en 1521. Resulta imposible, por el momento, dar explicación a esta anotación de Eubel ya que la documentación compostelana no registra intervención alguna de Don Diego como obispo; únicamente puede aventurarse la hipótesis de una renuncia o de un error en los registros consultados por este autor (la noticia sobre Don Diego procede del denominado Schedario Garampi).

${ }^{160}$ La toma de posesión del ya patriarca como arzobispo compostelano tiene lugar durante uno celebrado en abril de este año (AHDS, Fondo General, Leg. 219-1).

${ }^{161}$ AHDS, Fondo General. Leg. 1262, 25.

${ }^{162}$ AHDS, Fondo General. Leg. 1262, $\mathrm{f}^{\mathrm{D}} 31 \mathrm{r}$.

${ }^{163}$ Este conflicto se inserta plenamente entre las consecuencias de la reforma eclesiástica en la diócesis compostelana y se relaciona también con las disputas entre arzobispo y monasterio por la jurisdicción de Vilanova de Arousa, el coto del Pico Sacro y otras querellas de menor entidad (ACS, Leg. 282, 1).

"CUADERNOS DE ESTUDIOS GALLEGOS", Tomo XLVII, Fascículo 112, Santiago 2000. 
sólo parece encauzarse hacia los últimos años del siglo, cuando ya el grupo de canónigos ligados estrechamente al arzobispo es mayoritario ${ }^{164}$. Las disensiones posiblemente tienen su origen en la división del cabildo en 1459-60, cuando la ciudad está ocupada por el Conde de Trastámara; es entonces cuando la comunidad capitular se escinde, permaneciendo un grupo minoritario en la ciudad. Parece que otro tanto ocurre durante los años en que el arzobispo es prisionero de Bernal Yáñez de Moscoso y durante el gobierno Irmandiño. Da la sensación de que, progresivamente, se van aglutinando dos bandos diferenciados que, si bien no interfieren en el desarrollo cotidiano de la institución, sí aparecen con claridad en los momentos de crisis política, o ante las intervenciones directas del prelado en la vida común ${ }^{165}$. A medida que la situación se normaliza parecen descender los enfrentamientos directos, aunque siguen apareciendo crisis puntuales ${ }^{166}$. Resulta fundamental, a este respecto, la continua incorporación de familiares y criados del prelado. La ya mencionada impresión y venta de nuevos breviarios en 1496 provoca el conflicto más importante, que se prolonga durante algunos años, ya que hasta 1499 no encuentra solución.

Hay otros aspectos de la gestión fonsecana que se salen del ámbito estrictamente diocesano, como la defensa de la primacía de la Iglesia Compostelana y la intervención en los asuntos de la Iglesia Salmantina. Para preservar la primera, se inicia un proceso judicial contra la sede toledana y su prelado, Cisneros, que muy seguramente enturbia sus relaciones. La implicación -ya mencionada - en la vida catedralicia de Salamanca tiene un origen, por el momento impreciso, aunque puede relacionarse con la dignidad metropolitana del compostelano y con su dominante posición; la querella que enfrenta a Alonso de Fonseca III y al obispo Bobadilla -y que lleva a éste a emprender un destierro forzado- sobre la exención de la iglesia salmantina posiblemente tiene su causa en esta disputa.

\footnotetext{
${ }^{164}$ Es en la serie denominada Actas Capitulares y en los cuatro volumenes que recorren el período estudiado donde se encuentra la más importante fuente de noticias.

${ }^{165}$ Sobre la relación del cabildo con su arzobispo en el período 1460-1481 ver VÁZQUEZ BERTOMEU, M.: La institución notarial, v. I, pp. 31-36.

${ }^{166}$ Sería éste el caso, por ejemplo, del enfrentamiento con Diego de Muros (GARCÍA ORO, J.: Galicia en los siglos XIV y XV, v. I, pp. 475-476) o el de varios canónigos que perdieron su canonjía por privación arzobispal (VÁZQUEZ BERTOMEU, M.: Actas Capitulares. v. I, fo 179r, 189v.).
}

"CUADERNOS DE ESTUdios GALLEGOS", Tomo XLVII, Fascículo 112, Santiago 2000. 
A tenor de lo expuesto, la valoración del mandato del arzobispo Alonso de Fonseca se hace dificil. Las circunstancias que le toca vivir no son, desde luego, las ideales y, posiblemente, su carácter tampoco contribuye a suavizarlas. Es, sin embargo, evidente que la imagen forjada por la historiografía es incompleta, en ocasiones, simplista y, en general, fundamentada en un único aspecto de su gestión. Sólo el acercamiento a este período y personaje desde una perspectiva más global, nacida del estudio integral de toda la documentación existente permitirá no sólo una apreciación más acertada, sino que descubrirá los motivos y procesos que subyacen a muchos acontecimientos y actuaciones relacionadas con el prelado. 